\title{
Green Synthesized Gold Nanoparticles Using Viola betonicifolia Leaves Extract: Characterization, Antimicrobial, Antioxidant, and Cytobiocompatible Activities
}

\author{
Mincong Wang ${ }^{1}, *$ \\ Yue Meng ${ }^{1, *}$ \\ Huifeng Zhu' \\ Yong $\mathrm{Hu}^{\prime}$ \\ Chang-Peng $\mathrm{Xu}^{2}$ \\ Xiaomin Chao' \\ Wenqiang $\mathrm{Li}^{3}$ \\ Chengguo $\mathrm{Li}^{1}$ \\ Chenglong Pan'
}

'Department of Joint Surgery, The Fifth Affiliated Hospital of Southern Medical University, Guangzhou, People's Republic of China; ${ }^{2}$ Department of Orthopaedics, Guangdong Second Provincial General Hospital, Guangzhou, People’s Republic of China; ${ }^{3}$ Engineering Technology Research Center for Sports Assistive Devices of Guangdong, Guangzhou Sport University, Guangzhou, People's Republic of China

*These authors contributed equally to this work
Correspondence: Chenglong Pan;

Chengguo Li

Email pclgjwk@163.com;

356846516@qq.com
Introduction: Viola betonicifolia is a rich source of numerous secondary metabolites, such as alkaloids, flavonoids, tannins, phenolic compounds, saponins, triterpenoids, and so on, that are biologically active towards different potential biomedical applications. To broaden the potential use of Viola betonicifolia in the realm of bionanotechnology, we investigated the plant's ability to synthesize gold nanoparticles (Au NPs) in a green and efficient manner for the very first time.

Methods: The gold nanoparticles (VB-Au NPs) were synthesized using the leaves extract of Viola betonicifolia, in which plant's secondary metabolites function as both reducing and capping agents. The VB-Au NPs were successfully characterized with spectroscopic techniques. The antimicrobial properties of the VB-Au NPs were further explored against bacterial and mycological species. Additionally, their antioxidant, cytotoxic, and cytobiocompatibility properties were examined in vitro against linoleic acid peroxidation, MCF-7 cancer cells, and human mesenchymal stem cells (hMSCs), respectively.

Results: Results demonstrated that VB-Au NPs presented excellent antibacterial, antifungal, and biofilm inhibition performance against all the tested microbial species compared to plant leaves extract and commercially purchased chemically synthesized gold NPs (CH-Au NPs). Moreover, they also exhibited significant antioxidant potential, comparable to the external standard. The VB-Au NPs displayed good cytobiocompatibility with hMSCs and demonstrated excellent cytotoxic potential against MCF-7 cancer cells compared to $\mathrm{CH}-\mathrm{Au}$ NPs. The current work presents a green method for synthesizing VB-Au NPs with enhanced antioxidant, antimicrobial, cytotoxic and biofilm inhibition efficacy compared to $\mathrm{CH}-\mathrm{Au}$ NPs might be attributed to the synergistic effect of the nanoparticle's physical properties and the adsorbed biologically active phytomolecules from the plant leaves extract on their surface.

Conclusion: Thus, our study establishes a novel ecologically acceptable route for nanomaterials' fabrication with increased and/or extra medicinal functions derived from their herbal origins.

Keywords: Viola betonicifolia, gold NPs, antimicrobial, biofilm inhibition, antioxidant

\section{Introduction}

Nanobiotechnology is a combination of biology and nanotechnology that focuses on biocompatible manufacturing, environmentally safe and biogenic nanomaterials, nanoparticles, and their biological applications. ${ }^{1,2}$ Among all noble metal nanoparticles, gold nanoparticles have received considerable interest in recent years due to their tunable surface plasmon resonance (SPR) and unique optical and electrical characteristics, ${ }^{3}$ and their potential applications in the fields of chronic disease 


\section{Graphical Abstract}

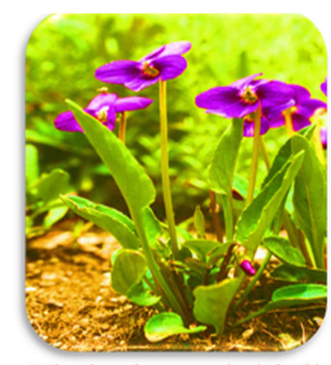

Viola betonicifolia

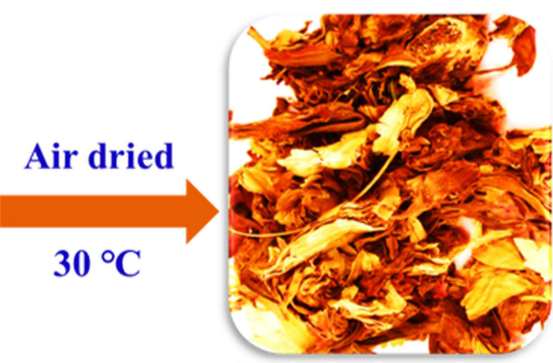

Dried plant leaves

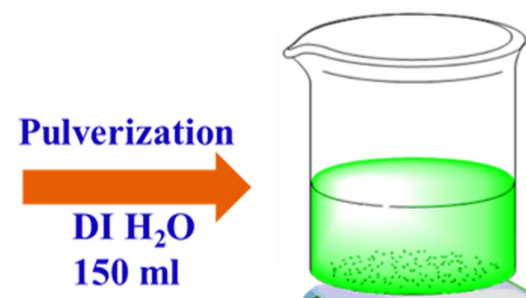

$60{ }^{\circ} \mathrm{C}, 60 \mathrm{~min}$

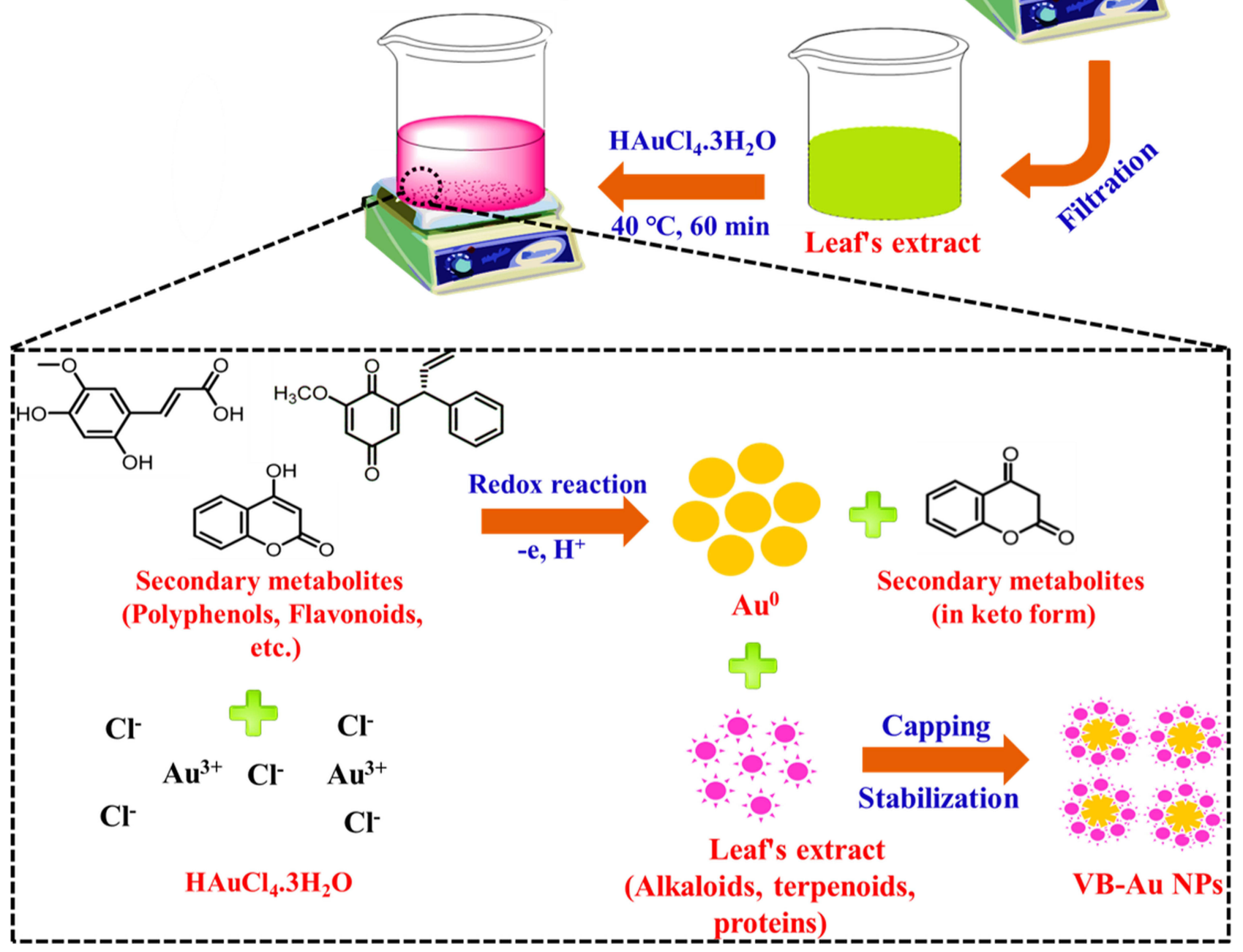

diagnostics and pharmaceuticals for the development of therapeutic agents, medical nanoengineering and biosensors. ${ }^{4}$ As is the case with all other metal nanoparticles, Au NPs are produced through physical, chemical, and biological processes. However, the physical and chemical synthesis of $\mathrm{Au}$ NPs causes significant environmental issues owing to the usage of hazardous chemicals, the release of toxic compounds, and the high cost. ${ }^{5,6}$ As a result, it has become a responsibility to emphasize a more cost-effective and ecologically beneficial alternative synthetic method. The recent development of green synthesis techniques for the biosynthesis of metallic 
nanoparticles has garnered considerable interest. In these green synthesis techniques, the synthesis of nanoparticles from plant leaf extracts is an especially promising option since leaf extract is easy to produce, cheap, stable, and scalable in contrast to other biomolecules. ${ }^{7}$ Plant-mediated synthesis of Au NPs using a leaf extract was developed for the first time by Shankar et al using lemongrass leaf extract. $^{8}$

Additionally, plant leaf extracts have been utilized as reducing and capping agents in the production of NPs. It has been shown that phytochemical components of plants, such as alkaloids, polyphenols, flavonoids, and terpenoids, promote metal ion reduction and the subsequent production of metal NPs. ${ }^{9,10}$ Furthermore, it is believed that biogenic phytomolecules may enhance the intrinsic properties of nanoparticles, such as antioxidant, antibacterial, and anticancer activities, via their absorption onto the nanoparticle surface. ${ }^{11-13}$ Thus, green synthesis utilizing plant leaf extracts improves the biocompatibility of nanoparticles and is responsible for the synergetic effect. ${ }^{14}$

Numerous plants and their components, such as stems, leaflets, flowers, seeds, and buds, have been utilized to synthesize various kinds of metallic and metal oxide nanoparticles. ${ }^{14-18}$ Among the plants utilized, some are either non-bioactive or bioactive but poisonous. For instance, many researchers have utilized Stevia leaf extract to synthesize various nanoparticles. However, in 2019, the FDA issued an import warning for leaves and crude extracts from the plant, citing concerns about its safety for use in meals or supplements and the potential for toxicity. ${ }^{19}$ Thus, nanoparticles for biological applications must be produced using biologically active plants with no harmful consequences.

Considering the enormous potential of Viola betonicifolia leaves extract as a source, this work aims to develop a green technique for synthesizing gold nanoparticles as an alternative to traditional methods. The leaf extract of Viola betonicifolia (L.), a member of the family Violaceae, was utilized to bioconvert gold ions to nanoparticles in this study. Viola betonicifolia (L.) grows wild in several countries, including Pakistan, India, Nepal, Sri Lanka, China, Malaysia, Myanmar, and Australia. ${ }^{20}$ This plant has been extensively used as a purgative, astringent, diaphoretic, anticancer, and antipyretic. It has been used to treat various conditions, including nervous disorders, epilepsy, cough, skin disorders, blood disorders, sinusitis, pharyngitis, kidney diseases, bronchitis, and pneumonia. $^{20,21}$ Numerous studies have shown that the whole leaves extract of Viola betonicifolia has a significant amount of biogenic phytomolecules, including alkaloids, flavonoids, tannins, phenolic compounds, saponins, and triterpenoids, among others, with a variety of biological applications. ${ }^{22,23}$ Nearly 200 naturally occurring active chemicals have been extracted and identified from different Viola species. ${ }^{24}$ Numerous plants have been used in the green synthesis of Au NPs nanoparticles; however, no report on the use of Viola betonicifolia exists (L.). As a result, we report for the first time the green synthesis of $\mathrm{Au}$ NPs utilizing the leaf extract of Viola betonicifolia (L.). Considering the health advantages of Viola betonicifolia leaves extract in the biomedical domain, the antibacterial, antifungal, anticancer, antioxidant, and biocompatibility activities of biologically produced Au NPs were investigated in this study.

\section{Materials and Methods}

All the chemicals used in this work were purchased from Sigma Chemicals Co (St. Louis, MS, USA) and Merck (Darmstadt Germany) and were analytical grade. The commercially available Au NPs functionalized with dodecanethiol (catalogue no. 660434) were purchased from Sigma-Aldrich with 3-5 nm size for comparative biological analysis. These nanoparticles are known as $\mathrm{CH}-\mathrm{Au}$ NPs synthesized nanoparticles.

\section{Collection of the Plant Material}

Fresh Viola betonicifolia leaves were collected near Lahore, Pakistan, and identified by Dr. Zaheer (Department of Botany, GC University, Pakistan). The plant's voucher specimen (Viola betonicifolia: GC. Herb. Bot. 213) was deposited at the herbarium of the Department of Botany, GC University, Lahore, Pakistan, and further study permission is not required under regional guidelines.

\section{Preparation of Leaves Extract of Viola betonicifolia}

The leaves extract of Viola betonicifolia was prepared by taking $20 \mathrm{~g}$ of fresh leaves of Viola betonicifolia. The leaves were thoroughly washed with deionized (DI) water to remove any impurities and dust and air-dried at $30{ }^{\circ} \mathrm{C}$. The dried leaves were cut into small pieces, pulverized with the help of a commercial blender, and the resulting plant's leaves powder was transferred to a $500 \mathrm{~mL}$ beaker. The $150 \mathrm{~mL}$ of DI water was then added and 
stirred at $60{ }^{\circ} \mathrm{C}$ for 60 minutes. Afterwards, the obtained leaves extract of Viola betonicifolia was cooled down to room temperature and then filtered. The filtrate was collected and stored at $4{ }^{\circ} \mathrm{C}$ in an airtight glass bottle for further use (Figure 1).

\section{Green Synthesis of Gold Nanoparticles}

For the green synthesis of gold NPs, one $\mathrm{mM}$ of $\mathrm{HAuCl}_{4} \cdot 3 \mathrm{H}_{2} \mathrm{O}$ was added to $25 \mathrm{~mL}$ of leaves extract of Viola betonicifolia (Figure 1). The resulting mixture was heated at $40{ }^{\circ} \mathrm{C}$ for 60 minutes with continuous stirring. When the colour of the reaction solution changed from yellow to ruby red, the formation of gold NPs was revealed. The gold NPs synthesized were separated by centrifugation at $3000 \mathrm{rpm}$ for 30 minutes from the reaction mixture. After centrifugation, the obtained NPs were washed with DI/ethanol three times, dried in an oven at $40{ }^{\circ} \mathrm{C}$ and calcined in a muffle furnace at $200{ }^{\circ} \mathrm{C}$ for 3 hours. Finally, the green synthesized gold NPs were stored in a glass bottle for further characterization and named VB-Au NPs.

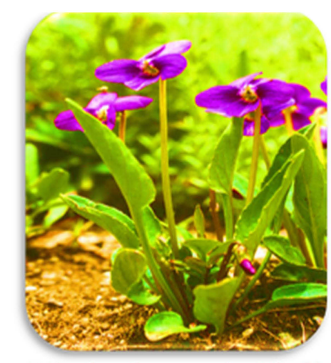

Viola betonicifolia

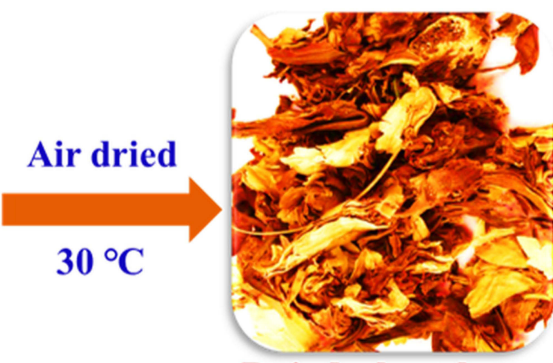

Dried plant leaves

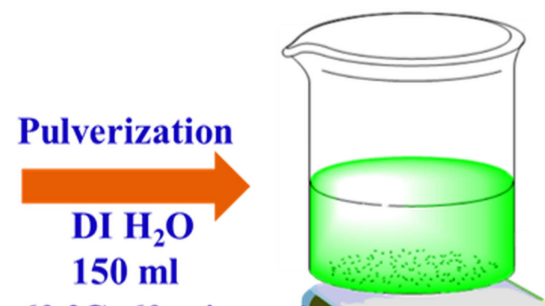

$60{ }^{\circ} \mathrm{C}, 60 \mathrm{~min}$

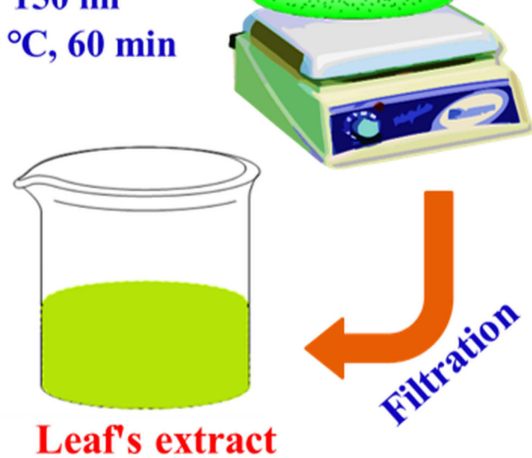

Leaf's extract

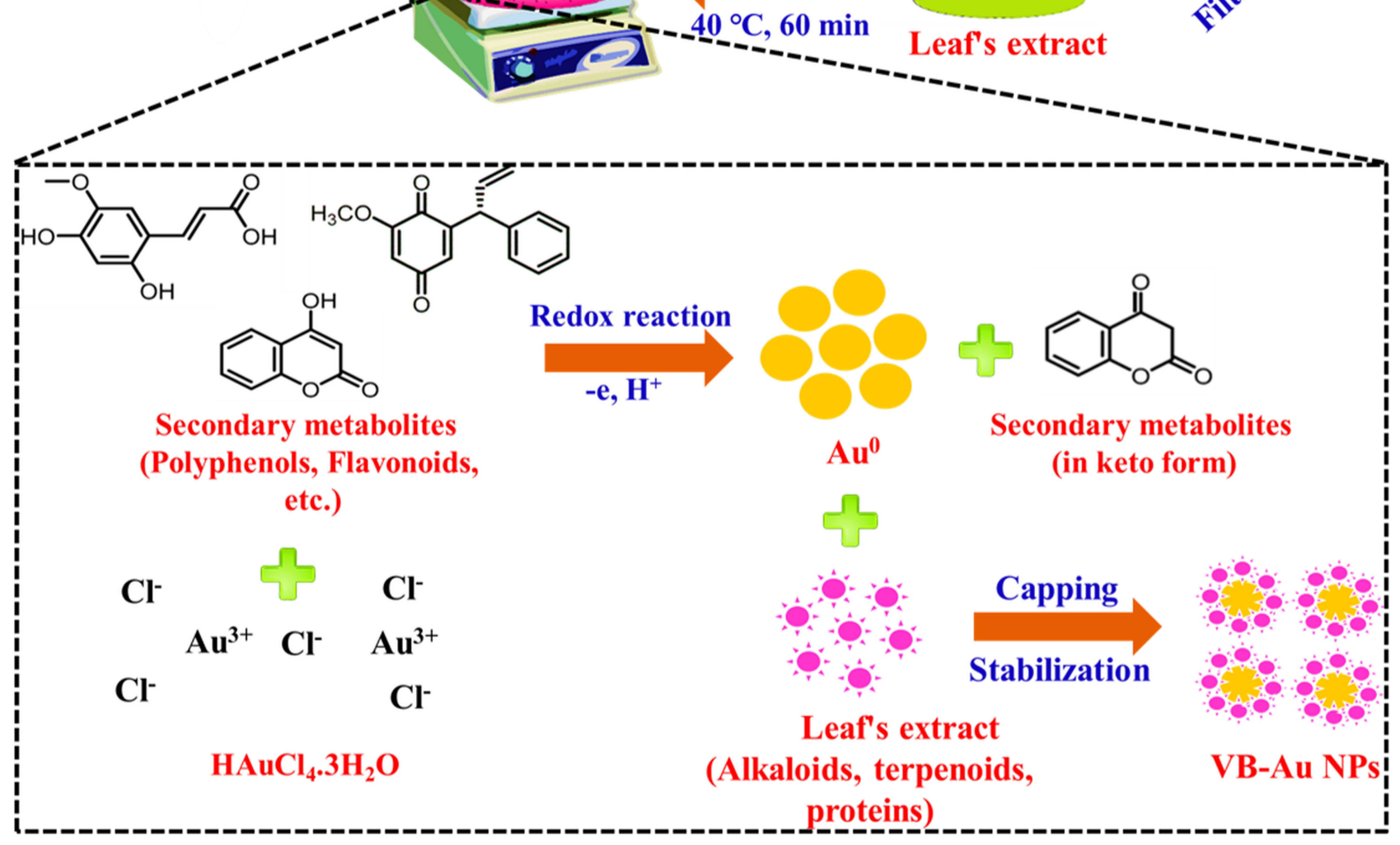

Figure I Schematic demonstration and possible synthesis mechanism for the green synthesized VB-Au NPs with the leaves extract of Viola betonicifolia. 


\section{Characterization of Green Synthesized VB-Au NPs \\ $X-R a y$ Diffraction}

The crystalline nature and phase purity of the VB-Au NPs were determined using the powder X-ray diffraction spectroscopy (XRD), which was carried out in a Bruker D2 PHASER with LYNXEYE XE-T detector (Haidian, Beijing, China) at a wavelength $(\lambda)$ of $0.154 \mathrm{~nm}$. The XRD spectra were recorded in the $2 \theta$ range $4-90^{\circ}$, with a scanning rate of $1 \% / \mathrm{min}$ and a slit width of $6.0 \mathrm{~mm}$.

\section{Energy-Dispersive X-Ray (EDX Spectroscopy)}

The chemical composition of synthesized VB-Au NPs was performed with an energy-dispersive X-ray (EDX) spectroscopy using Thermo Fisher Scientific Ultradry (Madison, WI, USA) attached with SEM.

\section{Transmission Electron Microscope (TEM)}

Transmission electron microscopy (TEM) images of the VB-Au NPs were obtained using a Tecnai F 12 microscope (FEI/Philips Tecnai 12 BioTWIN, Baltimore, MD, USA) operating at an acceleration voltage of $200 \mathrm{kV} .^{65}$ For TEM analysis, the samples were dissolved in methanol and sonicated at $25-30{ }^{\circ} \mathrm{C}$, and then deposited onto a carbon-coated copper grid. The copper grid was set aside for drying for 5-10 min after removing the excess solution.

\section{Zetasizer Dynamic Light Scattering (DLS)}

The stability and the particle size distribution of the synthesized VB-Au NPs were measured using a dynamic light scattering particle size analyzer (Malvern Zetasizer Nano ZS, Worcestershire, WR14 1XZ, UK) from 1 to 100 $\mathrm{nm}$ at $25-30{ }^{\circ} \mathrm{C} .{ }^{65}$

\section{UV-Visible Spectrophotometric Analysis}

Optical properties of the green synthesized VB-Au NPs were investigated using UV-Visible spectroscopy. For the UV-Vis experiment, the samples were firstly dissolved in DI water. The dissolved samples were then sonicated for 5 minutes at $25-30{ }^{\circ} \mathrm{C}$, the spectra were recorded as a function of wavelength on a Shimadzu 1700 spectrophotometer (Shimadzu, Columbia, Maryland, USA) from 200 to $800 \mathrm{~nm}$ at $25-30{ }^{\circ} \mathrm{C}$.

\section{Fourier Transform Infrared (FTIR) Spectroscopic Analysis}

FT-IR spectroscopy of the green synthesized VB-Au NPs and plant extracts were taken on a Perkin Elmer Spectrum 100
FT-IR Spectrophotometer (Bridgeport Avenue Shelton, CT 06484-4794, USA). The FT-IR spectra were collected in the frequency range of 450 to $4000 \mathrm{~cm}^{-1}$ at $25-30{ }^{\circ} \mathrm{C}$.

\section{Antibacterial Propensity of Green Synthesized VB-Au NPs}

The antibacterial propensity of the green synthesized VB$\mathrm{Au}$ NPs was evaluated on four bacterial species, which include Bacillus subtilis (ATCC ${ }^{\circledR}$ 6051TM), Pseudomonas aeruginosa $\left(\mathrm{ATCC}^{\circledR} 27853 \mathrm{TM}\right)$, Escherichia coli $\left(\mathrm{ATCC}^{\circledR}\right.$ 25922TM), and Staphylococcus aureus (ATCC $^{\circledR}$ 23235TM). In general, the strains of bacteria were seeded onto separate blood agar plates and then cultured for 24 hours at $37{ }^{\circ} \mathrm{C} .{ }^{66}$ After several bacterium colonies were grown on the plates, they were diluted with phosphate buffer saline (PBS). Their cell density was maintained to $1 \times 10^{7}$ colony forming units $(\mathrm{CFU})$ per $\mathrm{mL}$. Following that, $10 \mu \mathrm{L}$ of each bacterial culture was separately added to the wells of a 24-well microtiter plate with $1.0 \mathrm{~mL}$ of Mueller-Hinton broth (MHB). For each well, the final concentration of each bacterium was $1 \times 10^{5} \mathrm{CFU} / \mathrm{mL}$. A $50 \mu \mathrm{L}$ of each sample solution at $250 \mu \mathrm{g} / \mathrm{mL}$ concentration was then transferred to separate wells and incubated at $37{ }^{\circ} \mathrm{C}$ for 24 hours. The bacterial species were then counted in the wells using the serial dilution plate counting method. The antibacterial propensity was expressed in the form of $\log _{10}$ reduction in bacterial growth and \% killing using the following formulas:

$\log _{10}$ reduction $=\log _{10}\left(\mathrm{CFU}_{B I}\right)-\log _{10}\left(\mathrm{CFU}_{A I}\right)$,

\% killing $=\left(\mathrm{CFU}_{B I}-\mathrm{CFU}_{A I}\right) / \mathrm{CFU}_{B I} \times 100$.

where $\mathrm{CFU}_{B I}$ and $\mathrm{CFU}_{A I}$ are the $\mathrm{CFU}$ of bacterial strains before and after 24 hours of incubation, respectively, with the treatment of sample solutions.

\section{Live/Dead Bacteria Staining Assay}

Live and dead bacterial staining assays were carried out using a confocal laser scanning microscope (CLSM, FV1200, Olympus, Tokyo, Japan) to confirm the antibacterial activity of VB-Au NPs. The assay was performed following the methods reported by. ${ }^{42,67}$ Briefly, two nucleic dyes, membrane-permeant SYTO-9 and membrane impermeant propidium iodide (PI), were used for staining the live (green) and dead (red) bacteria, respectively. Bacteria were cultured in nutrient broth in an orbital shaker at $37^{\circ} \mathrm{C}$ for 24 hours to reach the stationary phase (approximately $10^{5}-10^{6}$ $\mathrm{CFU} / \mathrm{mL}$ ). After incubation, each bacterial strain was inoculated onto a sterilized covered glass coated with polyL-lysine in a 24-well plate. Then, each was incubated for 
an hour for bacterial cells attached to the cover glass. The suspended bacterial cells were then discarded, and each cover glass was gently rinsed three times with a saline solution. For the treatment, each bacterium cell on the cover glass was treated with $50 \mu \mathrm{L}$ of VB-Au NPs at a concentration of $250 \mu \mathrm{g} / \mathrm{mL}$ and then incubated at $37{ }^{\circ} \mathrm{C}$ for 24 hours. According to the manufacturer's instructions, bacteria cells on cover glass were stained with an alive and dead bacterial viability kit. Live and dead cells were analyzed with CLSM using an excitation wavelength of $483 \mathrm{~nm}$ and $535 \mathrm{~nm}$ for SYTO-9 and PI and an emission wavelength of $503 \mathrm{~nm}$ and $617 \mathrm{~nm}$ for SYTO-9 and PI, respectively. We only considered VB-Au NPs for live/dead staining assay as they presented excellent antibacterial properties in $\log _{10}$ reduction in bacterial growth.

\section{Reactive Oxygen Species (ROS Generation Investigations)}

Further killing of bacterial species due to the intracellular ROS generation was investigated using the CellROX ${ }^{\circledR}$ Green, as reported before. ${ }^{37}$ In a typical method, bacterial species (Pseudomonas aeruginosa and Staphylococcus aureus) at $10^{5} \mathrm{CFU} / \mathrm{mL}$ were treated with $50 \mu \mathrm{L}$ of synthesized VB-Au NPs at $250 \mu \mathrm{g} / \mathrm{mL}$ and incubated at $37^{\circ} \mathrm{C}$ for 24 hours. Following that, the microbial cells were incubated with CellROX ${ }^{\circledR}$ Green $(5 \mu \mathrm{M})$ for further 30 minutes at $37{ }^{\circ} \mathrm{C}$. Afterwards, CLSM was used to take images at $485 \mathrm{~nm}$ absorption wavelength and $520 \mathrm{~nm}$ emission wavelength. To evaluate the capacity of microbial cells to produce ROS, the results of NPs treated cells were compared to those treated with $1 \mathrm{mM} \mathrm{H}_{2} \mathrm{O}_{2}$ (positive control) and untreated cells (negative control).

\section{Antifungal Activity of Green Synthesized VB-Au NPs}

The antifungal activity of the green synthesized VB-Au NPs was estimated on four mycological species, which include C. albicans (ATCC ${ }^{\circledR}$ 10231TM), A. fumigatus (ATCC ${ }^{\circledR}$ 13073TM), A. flavus (ATCC ${ }^{\circledR}$ 9643TM), and $A$. niger (ATCC $\left.^{\circledR} 11414 \mathrm{TM}\right)$. The same antibacterial activity method as stated before was performed, but the seeding was accomplished using a Sabouraud-gentamicin-chloramphenicol (SGC) fungus agar plate, and the incubation temperature was maintained at $30{ }^{\circ} \mathrm{C} .{ }^{66}$ The antifungal activity was expressed in the form of $\log _{10}$ reduction in bacterial growth and $\%$ killing using the following formulas:

$\log _{10}$ reduction $=\log _{10}\left(\mathrm{CFU}_{B I}\right)-\log _{10}\left(\mathrm{CFU}_{A I}\right)$,

$\%$ killing $=\left(\mathrm{CFU}_{B I}-\mathrm{CFU}_{A I}\right) / \mathrm{CFU}_{B I} \times 100$. where $\mathrm{CFU}_{B I}$ and $\mathrm{CFU}_{A I}$ are the $\mathrm{CFU}$ of mycological strains before and after 24 hours of incubation, respectively, with the treatment of sample solutions.

\section{Biofilm Inhibition Efficiency of Green Synthesized VB-Au NPs}

The biofilm inhibition efficiency of the green synthesized VB-Au NPs was investigated against the different bacterium and mycological species in comparison to $\mathrm{CH}-\mathrm{Au}$ NPs and leaves extract of Viola betonicifolia. ${ }^{7,66}$ In summary, the biofilms of bacterium and mycological species were grown in a 96-well plate at $1 \times 10^{7} \mathrm{CFU} / \mathrm{mL}$ using TSB and RPMI agar, respectively. Both microbial species were incubated at $37^{\circ} \mathrm{C}$ and $30^{\circ} \mathrm{C}$ temperatures, respectively, for 24 hours. After removing the planktonic cells, each well was washed with PBS thrice. $50 \mu \mathrm{L}$ of each sample solution at the $250 \mu \mathrm{g} / \mathrm{mL}$ concentration was then transferred to each well and subsequently incubated to the well plate at $37^{\circ} \mathrm{C}$ for 24 hours. Then, each well was washed with PBS, and the staining agents were added $(10 \mu \mathrm{L}$ of phenazine methosulfate and $90 \mu \mathrm{L}$ of XTT). The microtiter well plate was then kept in the dark for 4 hours at $37^{\circ} \mathrm{C}$. Finally, optical density (OD) was measured at a wavelength of $492 \mathrm{~nm}$, and further biofilm inhibition efficiency in the form of percentage was calculated with the following formula:

Biofilm inhibition $(\%)=\left[\mathrm{OD}_{U T}-\mathrm{OD}_{T} / \mathrm{OD}_{U T}\right] \times 100$,

here, $\mathrm{OD}_{U T}$ and $\mathrm{OD}_{T}$ are the optical density of untreated and treated microbial species.

\section{Cytotoxic Potential of Green Synthesized VB-Au NPs Against MCF-7 Cells}

The cytobiocompatibility of the VB-Au NPs against the MCF-7 cells (commercially purchased from SigmaAldrich, Germany) in comparison to the CH-Au NPs and leaves extract of Viola betonicifolia was evaluated via the MTT protocol as reported. ${ }^{68}$ The MCF-7 cells were kept in Dulbecco's Modified Eagle's Medium (DMEM) in a humidified atmosphere comprising 5\% $\mathrm{CO}_{2}$ and $95 \%$ air at $37{ }^{\circ} \mathrm{C}$. To obtain cell confluency of up to $5 \times 10^{8}$ cells/well, the MCF-7 cells were cultured in $100 \mu \mathrm{L}$ of DMEM in a 96-well plate for 24 hours at $37^{\circ} \mathrm{C}$. After 100 $\mu \mathrm{L}$ of VB-Au NPs, leaves extract of Viola betonicifolia and $\mathrm{CH}-\mathrm{Au}$ NPs at a $120 \mu \mathrm{g} / \mathrm{mL}$ concentration was added to each well separately, containing cultured MCF-7 cells, the plate was further incubated for 24 hours at $37{ }^{\circ} \mathrm{C}$. Afterwards, the plate was centrifuged to remove the supernatant and subsequently washed using phosphate buffer 
saline (PBS) solution. A total $15 \mu \mathrm{L}$ of MTT labelling agent $(0.5 \mathrm{mg} / \mathrm{mL})$ was then added to each well; the plate was again placed in an incubator for incubation for 4 hours at $37^{\circ} \mathrm{C}$, and subsequently, $150 \mu \mathrm{L}$ of DMSO was added in each well to solubilize the undissolved crystals of formazan. The absorption maxima of formazan products in each well were measured at $570 \mathrm{~nm}$ using a Varian Eclipse spectrophotometer. The percentage of cell viability was calculated using the following formula:

$\%$ Cell viability $=\mathrm{OD}_{\text {sample }} / \mathrm{OD}$ control $\times 100$.

We next used a live/dead double staining kit to test the viability of MCF-7 carcinomatous cells using the fluorescence staining method (viable cells stained with green and dead cells with red). The exact process was conducted until carcinoma cells were treated with various samples $(10 \mu \mathrm{L}$ of $120 \mu \mathrm{g} / \mathrm{mL})$ and incubated after treatment. Following that, each well was incubated at $37{ }^{\circ} \mathrm{C}$ for 20 minutes with the staining solution (4 $\mu \mathrm{g} / \mathrm{mL})$. Fluorescence microscopy was used to capture the photographs $(535 / 617 \mathrm{~nm}$ and 361/497 nm excitation/emission wavelength for PI and Hoechst 33342).

\section{Antioxidant Activity of Green Synthesized VB-Au NPs in Terms of Linoleic Acid Peroxidation Inhibition}

The antioxidant activity of the VB-Au NPs was evaluated according to the linoleic acid (\%) inhibition method reported. ${ }^{27,69}$ For this purpose, $100 \mu \mathrm{g} / \mathrm{mL}$ concentration of each sample (VB-Au NPs, leaves extract of Viola betonicifolia, $\mathrm{CH}-\mathrm{Au}$ NPs and BHT) was added to the solution mixture of $99.99 \%$ ethanol $(10 \mathrm{~mL}), 0.2 \mathrm{M}$ sodium phosphate buffer ( $\mathrm{pH} 7.0,10 \mathrm{~mL})$, and linoleic acid $(0.13 \mathrm{~mL})$. The total volume of the resulting mixture was made up to $25 \mathrm{~mL}$ with DI and then incubated for 15 days at $40{ }^{\circ} \mathrm{C}$. The extent of oxidation was measured using the thiocyanate method. A $0.2 \mathrm{~mL}$ of each sample solution was taken and added to $10 \mathrm{~mL}$ of ethanol (75\%). Subsequently, $0.2 \mathrm{~mL} \mathrm{FeCl} 2(20 \mathrm{mM}$ in $3.5 \% \mathrm{HCl})$ and $0.2 \mathrm{~mL}$ of aqueous ammonium thiocyanate solution (30\%) was added, and then the reaction mixture was stirred for 3 minutes. Measurements of the absorption maxima were made at $500 \mathrm{~nm}$ wavelength. Percentage inhibition of linoleic acid was calculated according to the following formula:

$\%$ Inhibition $=100-[($ Absorbance of sample $) /($ absorbance of control) $\times 100]$.

\section{Cytobiocompatibility Analysis of Green Synthesized VB-Au NPs}

The cytobiocompatibility of the VB-Au NPs against the hMSCs in comparison to the CH-Au NPs and leaves extract of Viola betonicifolia was evaluated via the MTT protocol as reported. ${ }^{68}$ The hMSCs were kept in Dulbecco's Modified Eagle's Medium (DMEM) in a humidified atmosphere comprising $5 \% \mathrm{CO}_{2}$ and $95 \%$ air at $37{ }^{\circ} \mathrm{C}$. To obtain cell confluency of up to $5 \times 10^{8}$ cells/well, the hMSCs were cultured in $100 \mu \mathrm{L}$ of DMEM in a 96-well plate for 24 hours at $37^{\circ} \mathrm{C}$. After $10 \mu \mathrm{L}$ of VB-Au NPs, leaves extract of Viola betonicifolia and CH$\mathrm{Au}$ NPs at a concentration of $120 \mu \mathrm{g} / \mathrm{mL}$ was added to each well separately containing cultured hMSCs and the plate was further incubated for 24 hours at $37{ }^{\circ} \mathrm{C}$. Afterwards, the plate was centrifuged to remove the supernatant and subsequently washed using phosphate buffer saline (PBS) solution. A total $15 \mu \mathrm{L}$ of MTT labelling agent $(0.5 \mathrm{mg} / \mathrm{mL})$ was then added to each well; the plate was again placed in an incubator for incubation for 4 hours at $37^{\circ} \mathrm{C}$, and subsequently, $150 \mu \mathrm{L}$ of DMSO was added in each well to solubilize the undissolved crystals of formazan. The absorption maxima of formazan products in each well were measured at $570 \mathrm{~nm}$ using a Varian Eclipse spectrophotometer. The percentage of cell viability was calculated using the following formula:

$\%$ Cell viability $=$ OD sample $/ \mathrm{OD}$ control $\times 100$.

\section{Statistical Analysis}

All assays were performed for at least three biological replicates. The data is presented as the mean standard deviation (SD). The intergroup differences were estimated by one-way analysis of variance. Values were considered statistically significant at $P<0.05$.

\section{Results and Discussion Synthesis Mechanism of Green Synthesized VB-Au NPs}

To fabricate VB-Au NPs, the leaf extract of Viola betonicifolia was utilized as a reducing and capping agent. The formation of VB-Au NPs was visually tracked by observing the colour change caused by the addition of a metal salt precursor to leaf extract. The reaction mixture's colour shift from yellowish green to ruby red indicated the formation of the required gold NPs. This colour shift occurred as a consequence of the nanoparticle's surface plasmon resonance action., ${ }^{7,25,26}$ Several reports demonstrate that the leaves extract of Viola 
betonicifolia is a rich source of several biogenic phytomolecules, including alkaloids, flavonoids, tannins, phenolic compounds, saponins, triterpenoids, etc. ${ }^{20,21}$ During the biosynthesis process, these polyphenols and flavonoids might be functioned as reducing the gold ions to zero-valent species via reduction and oxidation reaction with the production of keto form products. Furthermore, other secondary metabolites (surfactants, proteins, alkaloids, etc.) present in the leaf extract of the Viola betonicifolia simultaneously stabilized and capped the zero-valent species of Au0, leading to the formation of nanoscale gold NPs (Figure 1). Similar synthesis mechanisms for gold and silver NPs using plant leaf extract were also reported by Khan et al and Hussain et al. ${ }^{27,28}$

\section{Characterization of Green Synthesized VB-Au NPs}

UV-Visible and FTIR studies of Viola betonicifolia and green-synthesized VB-Au NPs were performed to identify
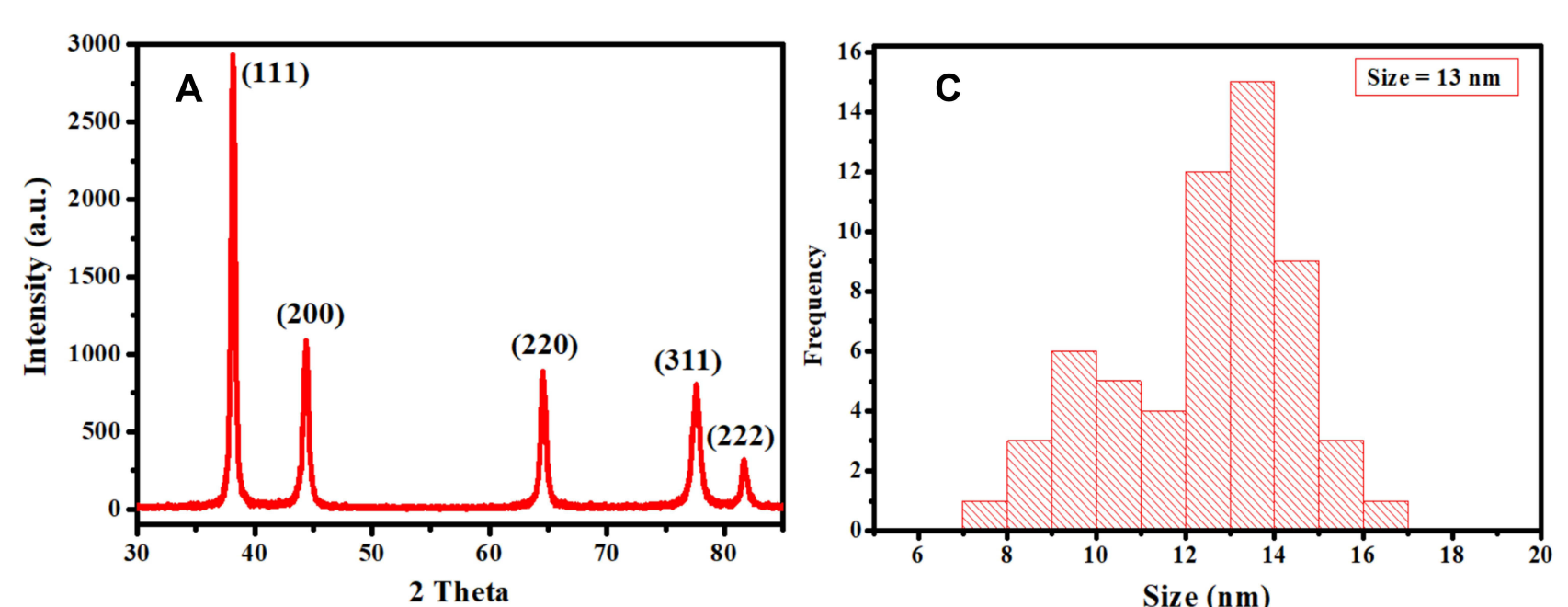

B
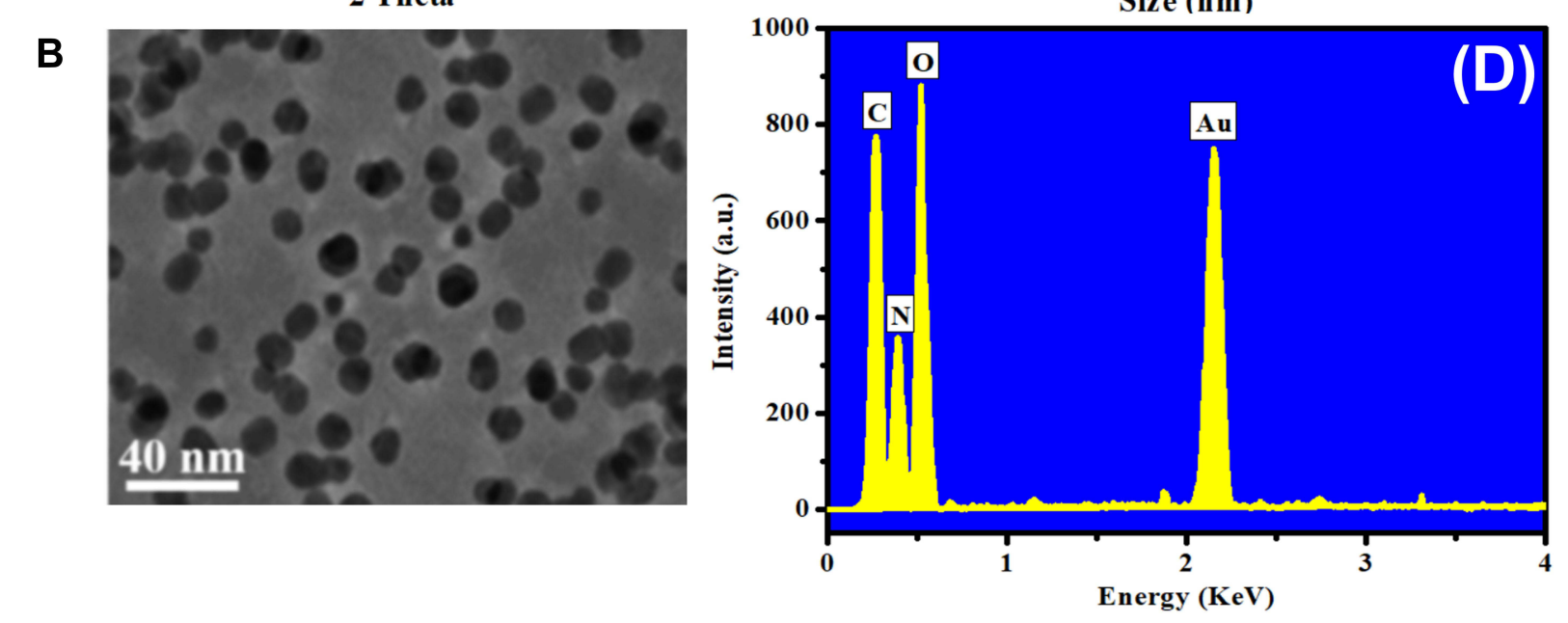

the absorbance maxima and various functional groups of secondary metabolites involved in reducing, stabilizing, and capping, respectively. Figures $2 \mathrm{~A}$ and $\mathrm{B}$ illustrate the UVVisible spectra of the leaf extract and the green synthesized gold NPs, respectively. Two absorption bands at 228 and 265 $\mathrm{nm}$ were seen in the leaf extract of Viola betonicifolia, indicating polyphenols and flavonoids as the literature demonstrates that they absorb UV window light. ${ }^{29}$ The highest absorption bands for VB-Au NPs were detected around 526 $\mathrm{nm}$ due to the surface plasmonic resonance phenomena. Khan et al and Mata et al reported a similar absorption spectrum for the green synthesized gold NPs. ${ }^{7,30}$ Figure $2 \mathrm{C}$ presents the FTIR spectra of plant leaves extract and indicating the several FTIR peaks of different molecular functionalities, including $2916 \mathrm{~cm}-1(\mathrm{C}-\mathrm{H}$ asymmetric stretch), $2842 \mathrm{~cm}-1$ (C-H symmetric stretch), $1672 \mathrm{~cm}-1(\mathrm{C}=\mathrm{C}), 1392 \mathrm{~cm}-1$ (C-N), $1178 \mathrm{~cm}-1$ (C-OH), $1064 \mathrm{~cm}-1$ (C-O-C), and $869 \mathrm{~cm}-1$ (aromatics). ${ }^{31,32}$ On the other hand, VB-Au NPs presented a similar FTIR signals pattern of different

Figure 2 UV-Visible spectra of (A) leave extract of Viola betonicifolia and (B) green synthesized VB-Au NPs. FTIR spectra of (C) leave extract of Viola betonicifolia and (D) green synthesized VB-Au NPs. 
functional groups to the plant extract with slight shifting in intensity and wavenumbers (Figure 2D). Thus, our findings established that green-synthesized VB-Au NPs are entirely capped with biologically active secondary metabolites from plant leaf extract containing such functional groups.

$\mathrm{XRD}$ analysis was further carried out to analyze the crystallinity of the VB-Au NPs synthesized using the leaves extract of Viola betonicifolia. Figure 3A shows an XRD pattern of the VB-Au NPs. XRD pattern demonstrates five distinguish peaks attributed to (111), (200), (220), (311), and (222) crystal plane of VB-Au NPs (JCPDS no. 00-0040784). ${ }^{7,33,34}$ Moreover, the XRD pattern indicates that the VB-Au NPs are highly crystalline, as evident from the intensity of the peaks. Figure 3B presents the TEM images of VB-Au NPs. The TEM image depicts that the synthesized VB-Au NPs are spherical with homogeneous dispersity. The particle size of the synthesized VB-Au NPs was estimated to be $13 \mathrm{~nm}$ using DLS, as shown in Figure 3C. To determine the chemical composition of the VB-Au NPs, the EDX analysis was then conducted. Figure 3D shows the EDX pattern. EDX spectra indicate four characteristic peaks corresponding to carbon, oxygen, nitrogen, and gold. Besides gold, the EDX peaks $(\mathrm{C}, \mathrm{O}$, and $\mathrm{N})$ were attributed to the adsorption of secondary metabolites from Viola betonicifolia leaves extract on the surface of VB-Au NPs. Thus, these characterization findings confirmed the effective synthesis of VB-Au NPs using a leaf extract of Viola betonicifolia.

\section{Antibacterial Performance of Green Synthesized VB-Au NPs}

The antibacterial performance of VB-Au NPs was determined in terms of $\log _{10}$ reduction and \% killing efficiency of bacterial strains compared to leaves extract of Viola betonicifolia and CH-Au NPs. The results are presented in Figure $4 \mathrm{~A}-\mathrm{C}$. The outcomes have been shown that the
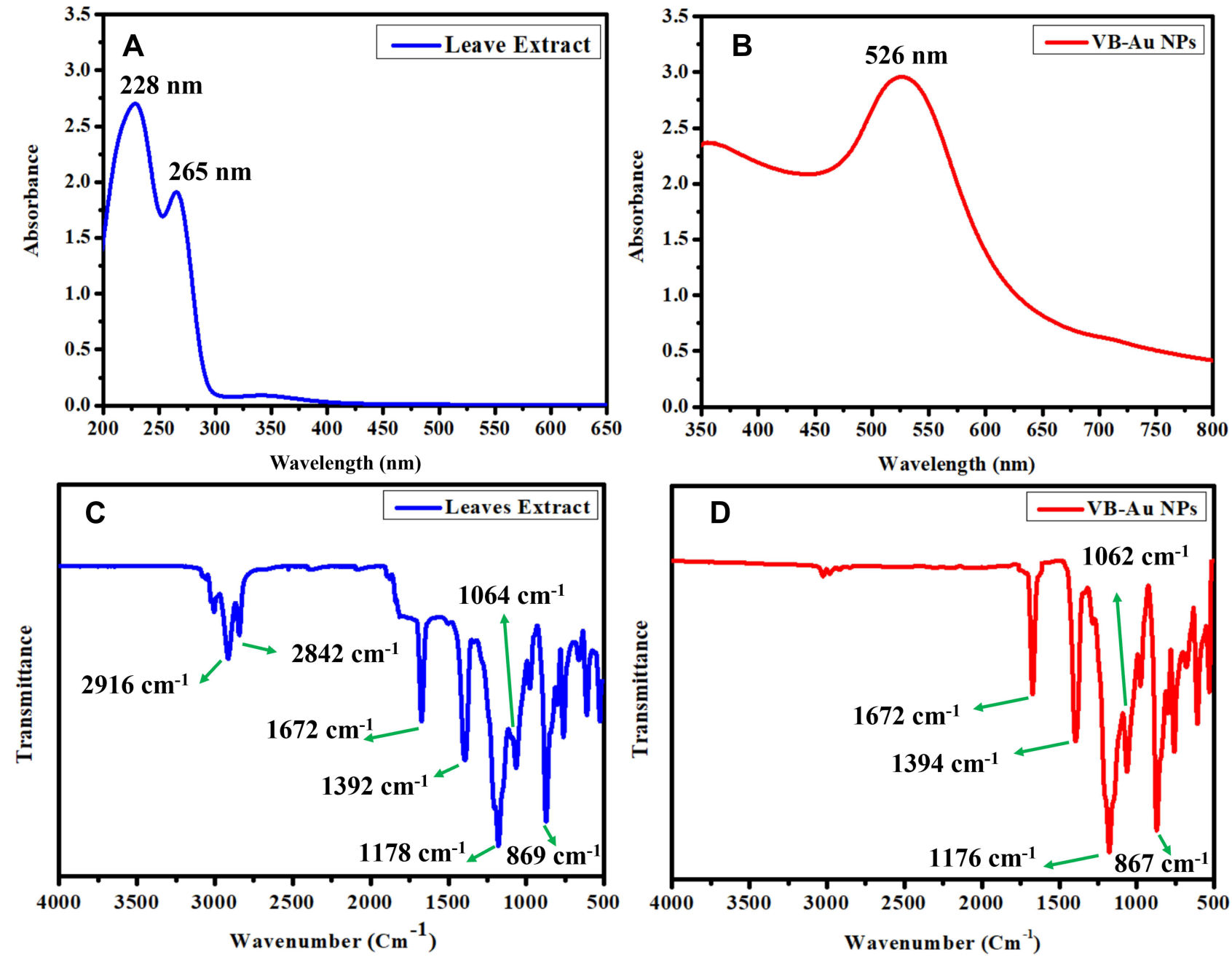

Figure 3 (A) XRD pattern, (B) TEM image, (C) size distribution, and (D) EDX pattern for the green synthesized VB-Au NPs. 


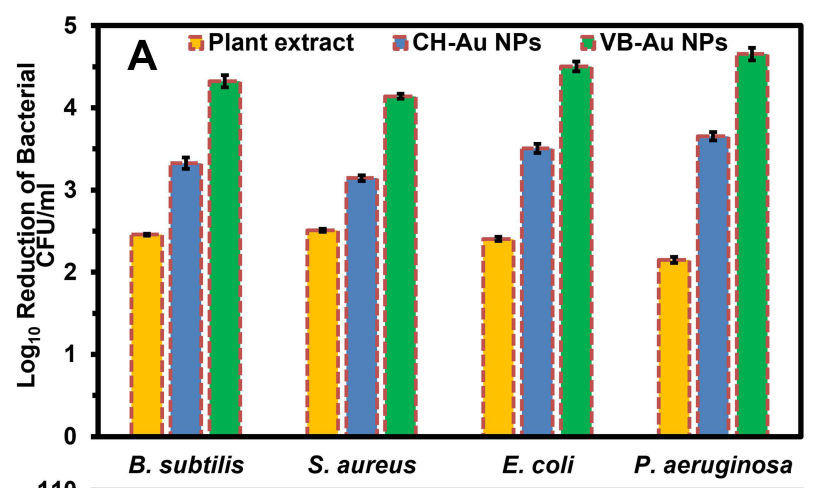

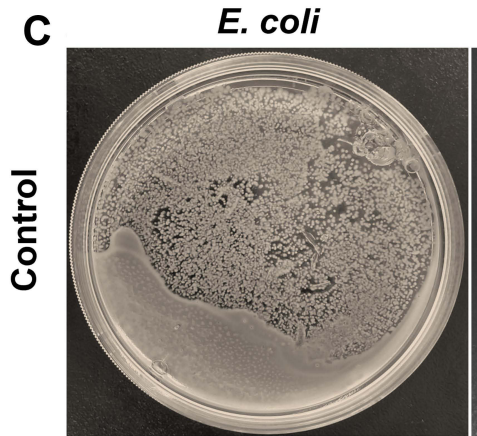

VB-Au NPs

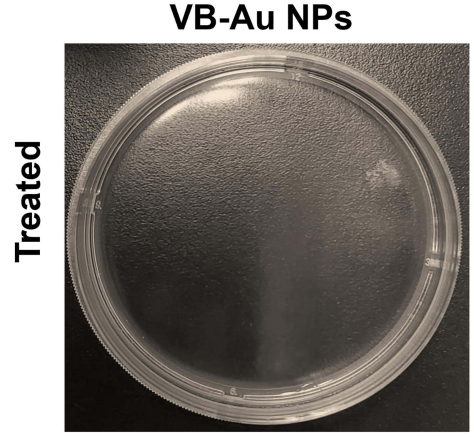

P. aeruginosa

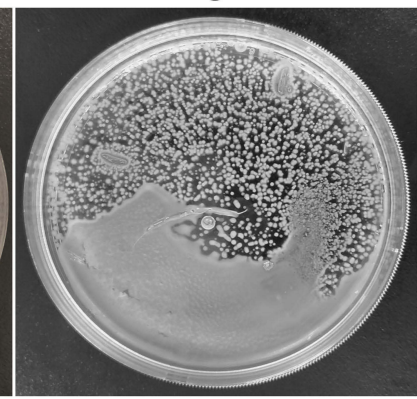

VB-Au NPs

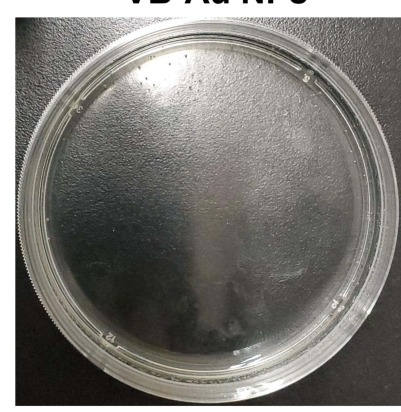

Figure 4 Antibacterial activity of VB-Au NPs in terms of $(\mathbf{A}) \log 10$ reduction $(p<0.0004)$ and $(\mathbf{B}) \%$ killing efficiency of bacterial strains in comparison to leaves extract of Viola betonicifolia and $\mathrm{CH}-\mathrm{Au}$ NPs $(p<0.0004)$. (C) Representative images of control and treated $E$. coli and P. aeruginosa with VB-Au NPs.

synthesized VB-Au NPs displayed 4.14, 4.32, 4.50, and 4.65 $\log _{10}$ reductions in CFU of S. aureus, B. subtilis, E. coli, and $P$. aeruginosa, respectively, with more than $82 \%$ killing efficiency. On the other hand, $\mathrm{CH}-\mathrm{Au}$ NPs exhibited the least antibacterial activity than VB-Au NPs, as shown in Figure 4A and B. It is worth noting that the leaves extract of Viola betonicifolia has demonstrated significant antibacterial behaviour and percent killing performance against all bacteriological species tested. This indicates that the leaves extract of Viola betonicifolia possesses pharmacologically important phytomolecules capable of killing bacterial strains effectively. ${ }^{20,35}$ Moreover, statistical significance $(p<$ $0.0004)$ was observed in the antibacterial activity results.

LIVE and DEAD staining assays were further used to evaluate the interaction of synthesized VB-Au NPs with bacterial cells and subsequent cell death upon labelling with SYTO 9 and PI. The permeability of the bacterial membrane to these dyes is dependent on the cellular membrane's potential, which allows for the differentiation of alive and dead cells. SYTO 9 is a membrane-permeant dye, while PI is a membrane-impermeant dye that permeates only through dead cells' perforated membranes. ${ }^{36,37}$ As illustrated in Figure 5A-D, the untreated B. subtilis, S. aureus, E. coli, and P. aeruginosa cells stained green, suggesting that they were intact and alive. At the same time,
VB-Au NPs treated cells fluoresced red. This revealed that VB-Au NPs triggering cell death had an effect on the integrity and permeability of the cell membrane.

Microbial strains have been demonstrated to be destroyed by oxidative stress caused by intracellular ROS production. ${ }^{38}$ Metal NPs interact with bacteria to generate reactive oxygen species (ROS), which may cause oxidative stress inside the cell, destroying organelles and biomolecules. Figure 6 shows the results of the CellROX ${ }^{\circledR}$ Green test used to evaluate oxidative stresses in microbial cells after treatment with VB-Au NPs. In the control of both bacterial cells, no intracellular ROS species were produced, while both bacteria treated with VB-Au NPs generated ROS that was comparable to that produced by $\mathrm{H}_{2} \mathrm{O}_{2}$. These findings suggest that one explanation for the produced VB-Au NPs' outstanding antibacterial activity is reactive oxygen species (ROS) production, which causes bacterial cells to die.

The superior antibacterial action of VB-Au NPs can be due to the synergy influence of the nanoparticle's physical characteristics and the adsorption of biologically active phytomolecules from the leaves extract of Viola betonicifolia on their surface. ${ }^{7,27,39-42}$ The results further demonstrated that the synthesized VB-Au NPs appeared more active towards the Gram-negative compared to that of Gram-positive bacteriological species. This may be due to structural and 


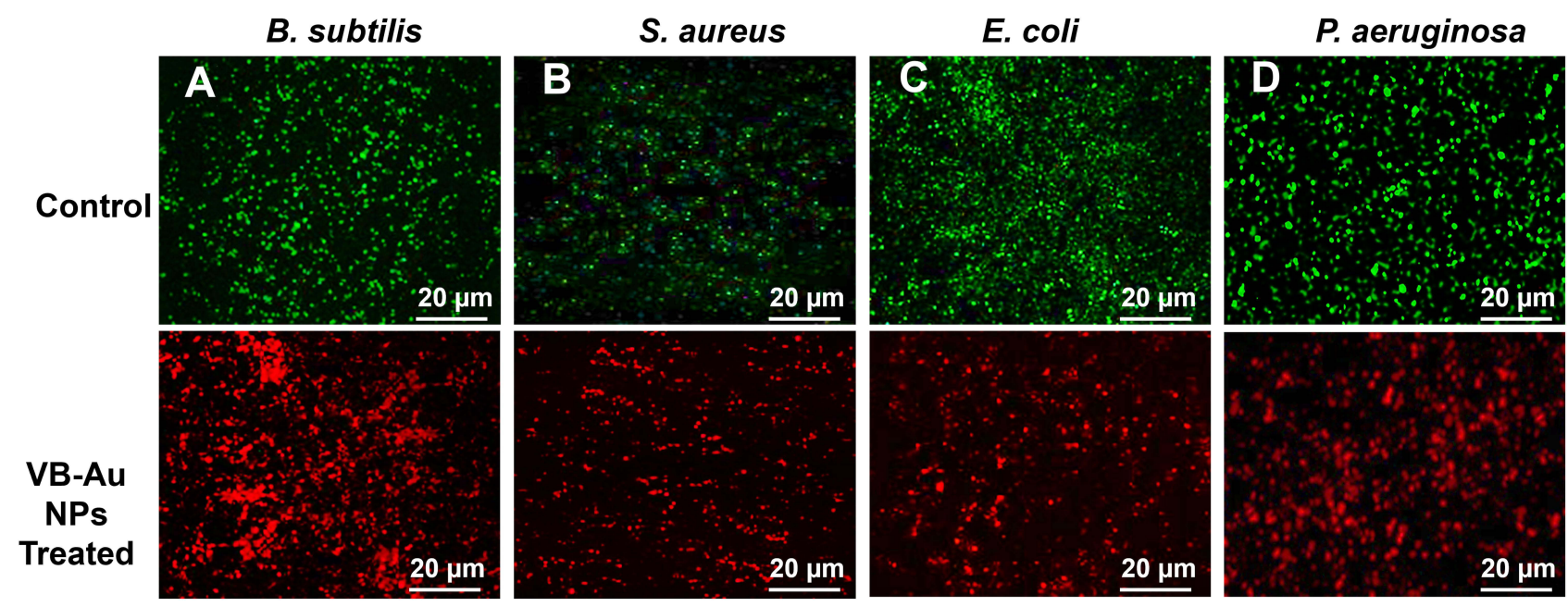

Figure 5 CLSM images of $B$. subtilis (A), S. aureus (B), E. coli (C), and $P$. aeruginosa (D). Green and red represent alive and dead bacterial cells, respectively.

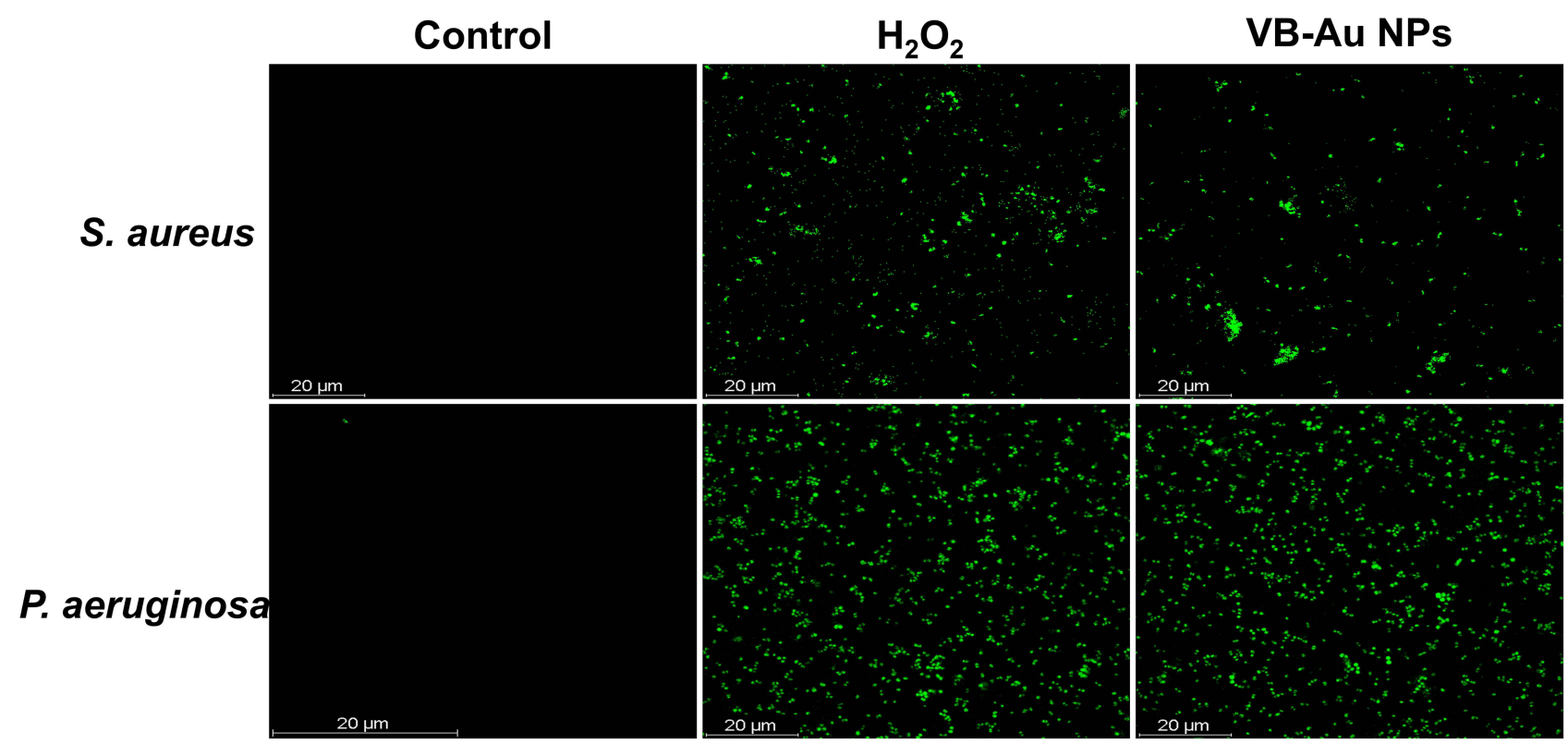

Figure 6 CLSM images of ROS generation in untreated (control) and treated bacteria with hydrogen peroxide (H2O2) and synthesized VB-Au NPs.

compositional variations between Gram-negative and Grampositive bacterial strains' cell walls (Figure 7). ${ }^{13,43,44}$ Grampositive bacteria have a dense coating of peptidoglycan to which teichuronic and teichoic acids are covalently bound. However, Gram-negative bacteria have a thin coating of peptidoglycan with an exterior coating of negatively charged lipopolysaccharides. ${ }^{7,39,45}$ Due to such reasons, the synthesized VB-Au NPs are seen to have a more significant inhibitory effect on Gram-negative than on Gram-positive bacterial species. Bindhu et al and Boomi et al were also reported the same more inhibitory activity of gold NPs synthesized using different plants. ${ }^{43,44}$
Antibacterial activity of metal nanoparticles has been ascribed to their ability to cause oxidative or physical damage to bacterial cells. ${ }^{46-54}$ In this study, live/dead staining and the intracellular ROS generation confirmed that the destruction of the microbial cell membrane and subsequent cell death induced by VB-Au NPs were caused by the membrane permeabilization and production of ROS species. The penetrated VB-Au NPs upon membrane impairment and generated ROS species might be further intercalated with different cellular organelles (membrane proteins, DNA, mitochondria, ribosomes, etc.), leading to their denaturation and arresting them 


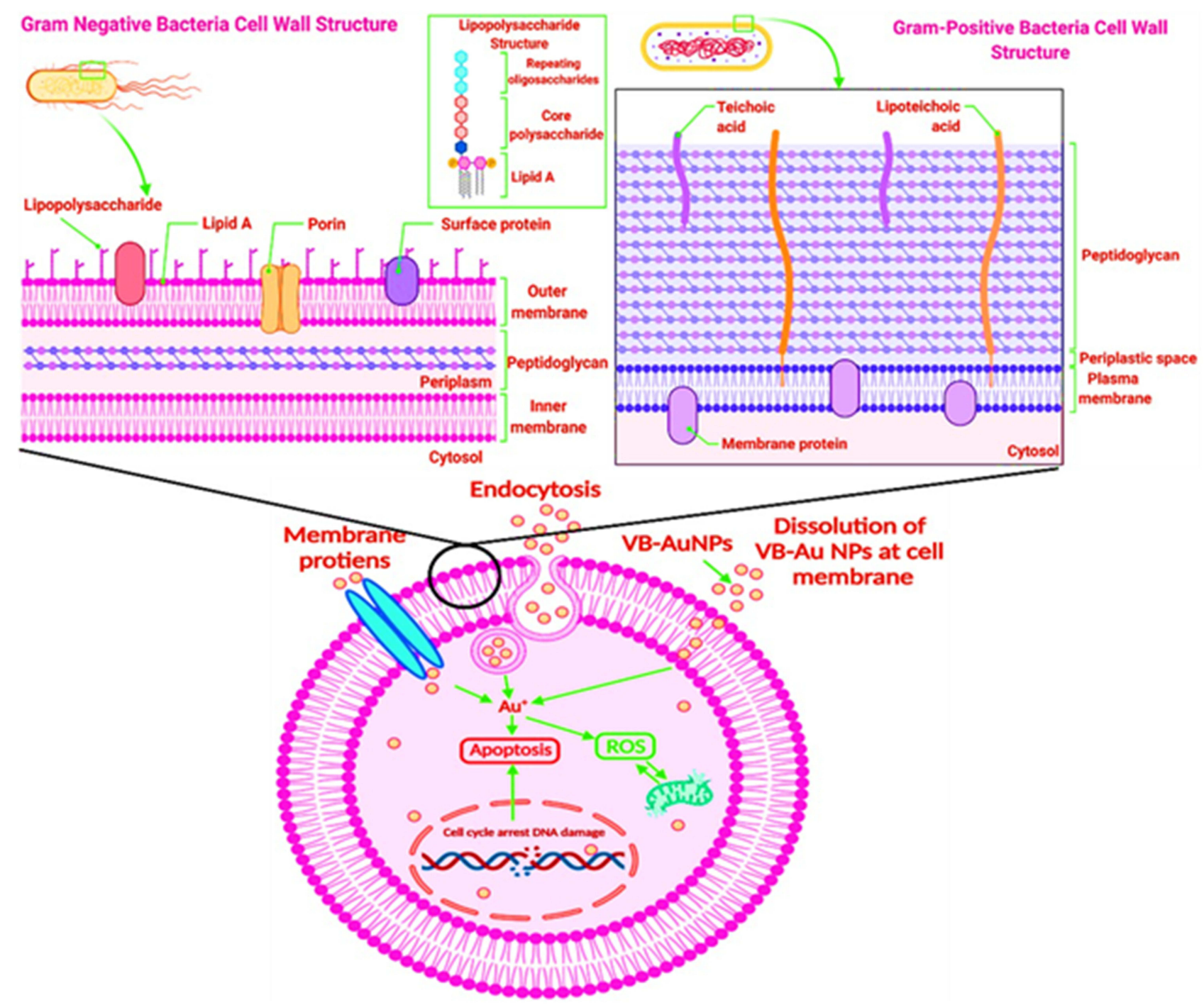

Figure 7 Comparison of Gram-negative and Gram-positive bacterial cell wall and proposed antibacterial mechanism of green synthesized VB-Au NPs. Created with BioRender.com.

from functioning (Figure 7). ${ }^{55}$ However, studies have demonstrated that gold nanoparticle's antibacterial performance is not due to ROS production. ${ }^{56}$ In our study, ROS generation might be attributed to phytomolecules adsorbed on the surface of the nanoparticles from the plant leaf extract.

Given the consistency and uniformity of the findings, we suggest that the antibacterial performance of VB-Au NPs is the consequence of the combined impact of physical and oxidative destructions and the following cellular changes: (1) the interaction of VB-Au NPs with lipopolysaccharides and cell surface proteins results in the annihilation of the cell membrane; (2) the disintegration of the microbial cell membrane increased membrane permeability, resulting in the seepage of intracellular biomolecular functionality; (3) the generation of intracellular ROS species impairs the microscopic ability of the cell (Figure 7).

\section{Antifungal Activity of Green Synthesized VB-Au NPs}

In contrast to leaves extract of Viola betonicifolia and $\mathrm{CH}-\mathrm{Au}$ NPs, the antifungal activity of synthesized VB$\mathrm{Au}$ NPs was determined in terms of $\log _{10}$ reduction and $\%$ killing efficiency of mycological strains. Figure $8 \mathrm{~A}$ and $\mathrm{B}$ illustrate the findings. The results indicated that the synthesized VB-Au NPs significantly reduced the CFU of C. albicans, A. fumigatus, A. flavus, and $A$. niger by $3.32,4.0$, and $3.55 \log _{10}$ reductions, respectively, with an efficiency of more than $67 \%$. CH-Au $\mathrm{NPs}$, on the other hand, demonstrated significantly 

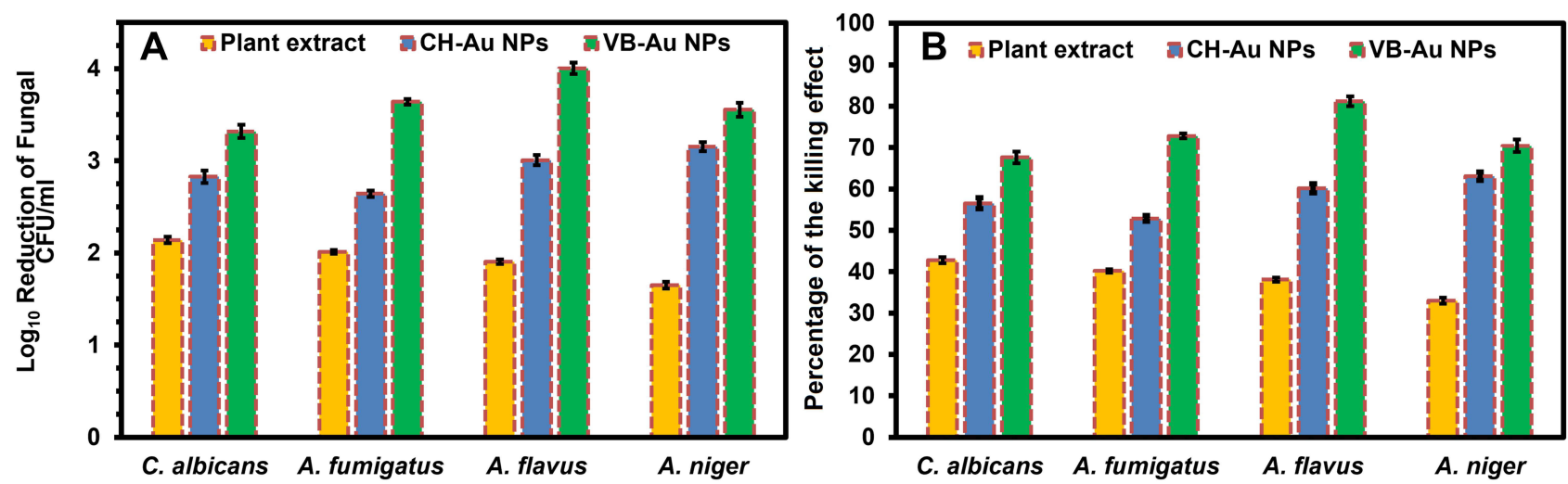

Figure 8 Antifungal activity of VB-Au NPs in terms of $(\mathbf{A}) \log 10$ reduction $(p<0.0008)$ and $(\mathbf{B}) \%$ killing efficiency $(p<0.0008)$ of fungal strains in comparison to leaves extract of Viola betonicifolia and CH-Au NPs.

lower antifungal activity than VB-Au NPs, as shown in Figure $8 \mathrm{~A}$ and $\mathrm{B}$. It is worth noting that the leaves extract of Viola betonicifolia also demonstrated substantial antifungal activity and percent killing efficiency against all tested mycological strains. This indicates that the Viola betonicifolia leaf extract contains biologically active phytomolecules that are particularly effective at destroying fungal strains. ${ }^{57}$ Additionally, the superior antifungal activity of VB-Au NPs can be due to the synergistic impact of the nanoparticle's physical properties and the adsorbed biologically active phytomolecules from the leaves extract of Viola betonicifolia on their surface [31-35]. Balasubramanian et al, Dananjaya et al, and Jayaseelan et al have also reported effective antifungal activity of gold NPs synthesized using the extract of Jasminum auriculatum, Spirulina maxima, Abelmoschus esculentus, respectively, against different fungal strains. ${ }^{58-60}$

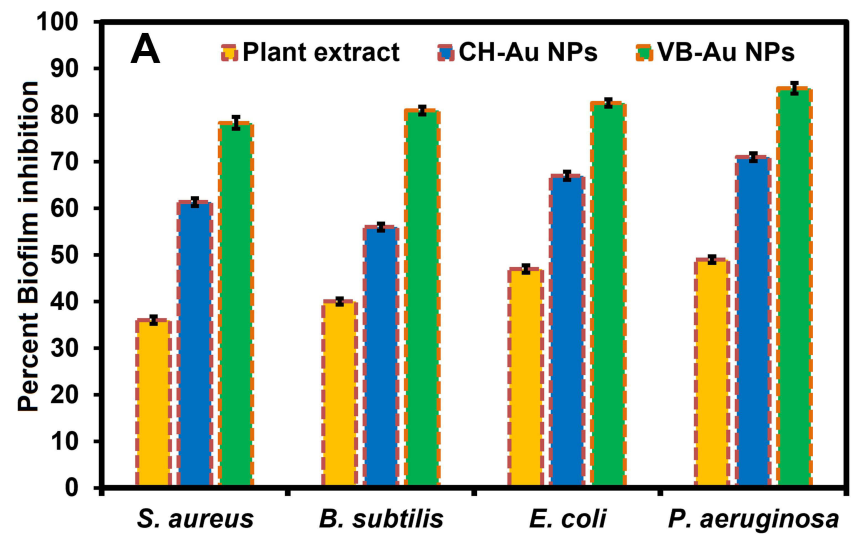

\section{Biofilm Inhibition Investigations of Green Synthesized VB-Au NPs}

The biofilm inhibition activity of VB-Au NPs was evaluated against infectious bacterial, and mycological species in contrast to Viola betonicifolia leaves extract and $\mathrm{CH}-\mathrm{Au}$ NPs. Figure 9A and B illustrate the findings. The findings indicate that the VB-Au NPs exhibited substantial biofilm inhibitory activity, inhibiting the production of biofilms of both bacterial and mycological strains. Although $\mathrm{CH}-\mathrm{Au}$ NPs inhibited the production of biofilms in both microbial species, they were less than VB-Au NPs synthesized with Viola betonicifolia leaves extract. Moreover, the Viola betonicifolia leaves extract demonstrated good biofilm inhibition performance, as evident from Figure 9A and B. The remarkable biofilm inhibition efficiency of the synthesized VB-Au NPs may result from the synergy between their physical properties and the incorporation

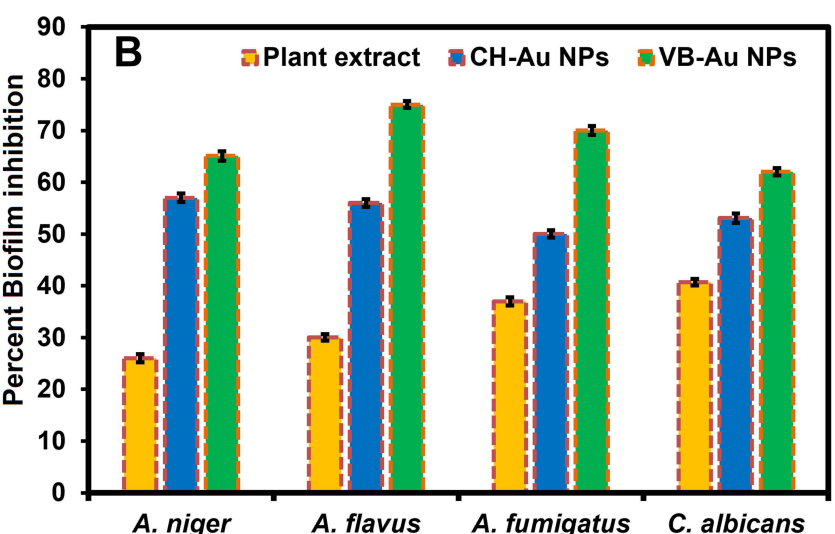

Figure 9 Biofilm inhibition performance of the synthesized VB-Au NPs against the $(\mathbf{A})$ bacterial $(p<0.006)$ and (B) fungal strains $(p<0.004)$ in comparison to Viola betonicifolia leaves extract and $\mathrm{CH}-\mathrm{Au}$ NPs. 
of phytomolecules from Viola betonicifolia leaves extract on the nanoparticle's surface.

\section{Cytotoxicity Activity of Green Synthesized VB-Au NPs Against MCF-7 Cells}

By comparing to Viola betonicifolia leaves extract, and $\mathrm{CH}-\mathrm{Au}$ NPs, the cytotoxicity efficacy of VB-Au NPs was determined. The results showed that the therapeutic potential of all specimens was dose-dependent (Figure 10). When all samples were concentrated up to $120 \mu \mathrm{g} / \mathrm{mL}$, the most significant cytotoxic impact on MCF-7 melanoma cells was found. The VB-Au NPs demonstrated superior cytotoxicity at all dosage levels than Viola betonicifolia leaves extract and CH-Au NPs. The remarkable cytotoxic effect of the synthesized VB-Au NPs may be a function of synergistic effects between their physical properties and the incorporation of phytomolecules from Viola betonicifolia leaves extract on their surface. It is noteworthy that the leaves extract of Viola betonicifolia was similarly efficient against MCF-7 cancer cell lines. This demonstrates that the leaves extract of Viola betonicifolia comprises pharmacologically significant phytomolecules capable of effectively destroying malignant cells.

Moreover, CLSM was also utilized to validate the cytotoxic effects of the Viola betonicifolia leaves extract, $\mathrm{CH}-\mathrm{Au}$ NPs, and VB-Au NPs on MCF-7 malignant cells by performing live and dead fluorescence labelling experiments. Figure 11A-D shows MCF-7 malignant cells stained with Hoechst 33342 and PI dye. Hoechst 33342 is a membrane- permeant dye that can stain both living and dead cells through DNA intercalating, while PI is a membrane-impermeant dye that penetrates only through ripped membranes and can stain only dead cells. The results indicated that VB$\mathrm{Au}$ NPs seem to be the most lethal to MCF-7 cancer cells, destroying nearly all cancerous cells. However, $\mathrm{CH}-\mathrm{Au}$ NPs showed a modest detrimental effect on MCF-7 cancerous cells. It is essential to mention that leaf extract was equally toxic to MCF-7 cancerous cells, indicating that Viola betonicifolia leaves extract comprises phytochemicals with pharmaceutical activity. These results are consistent with those obtained from MTT studies.

\section{Antioxidant Activity of Green Synthesized VB-Au NPs}

Antioxidant activity of the newly synthesized VB-Au NPs was investigated compared to the leaves extract of Viola betonicifolia, $\mathrm{CH}-\mathrm{Au}$ NPs, and external standard (BHT). Figure 12A illustrates the findings. The anti-linoleic acid peroxidation activity of newly synthesized VB-Au NPs was superior to that of Viola betonicifolia leaves extract and CH-Au NPs, although a little less than BHT. On the other hand, $\mathrm{CH}-\mathrm{Au}$ NPs exhibited the lowest antioxidant function, exhibiting the lowest percentage of anti-linoleic acid peroxidation. Additionally, the leaves extract of Viola betonicifolia demonstrated superior antioxidant function by inhibiting linoleic acid peroxidation compared to $\mathrm{CH}$ Au NPs. These findings suggested that Viola betonicifolia leaves extract contains a high concentration of natural antioxidants. $^{20,61}$ Furthermore, the inclusion of

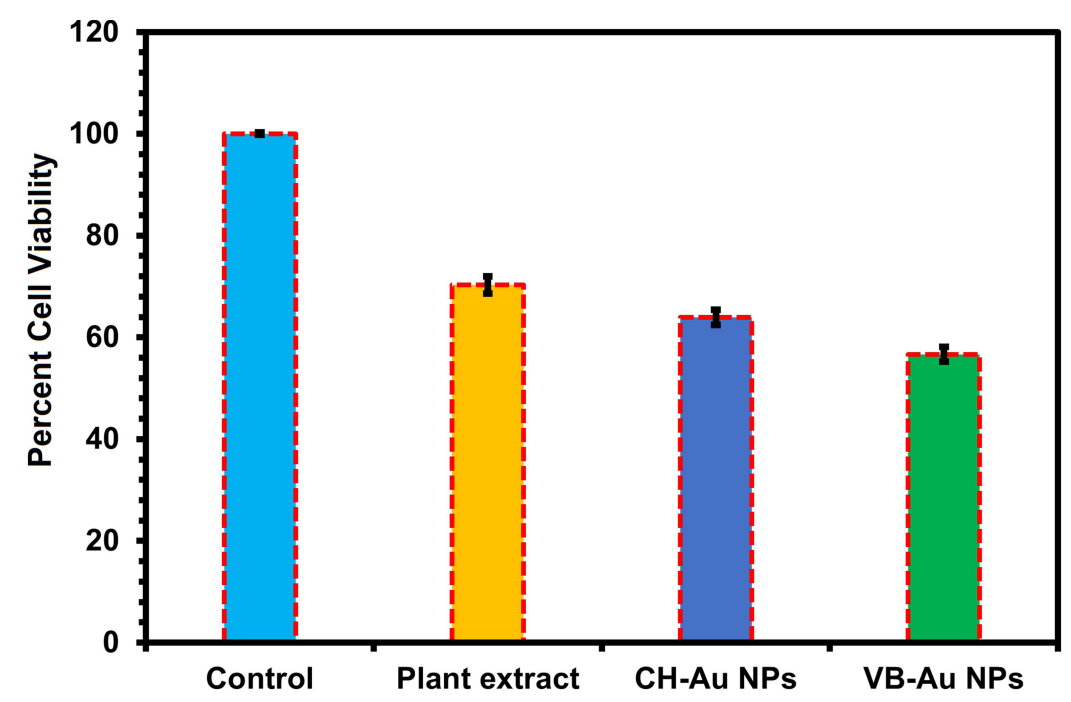

Figure 10 Cytotoxic potential in terms of cell viability percentage against MCF-7 carcinoma cells treated with Viola betonicifolia leaves extract, CH-Au NPs, and VB-Au NPs $(p<0.0001)$. 


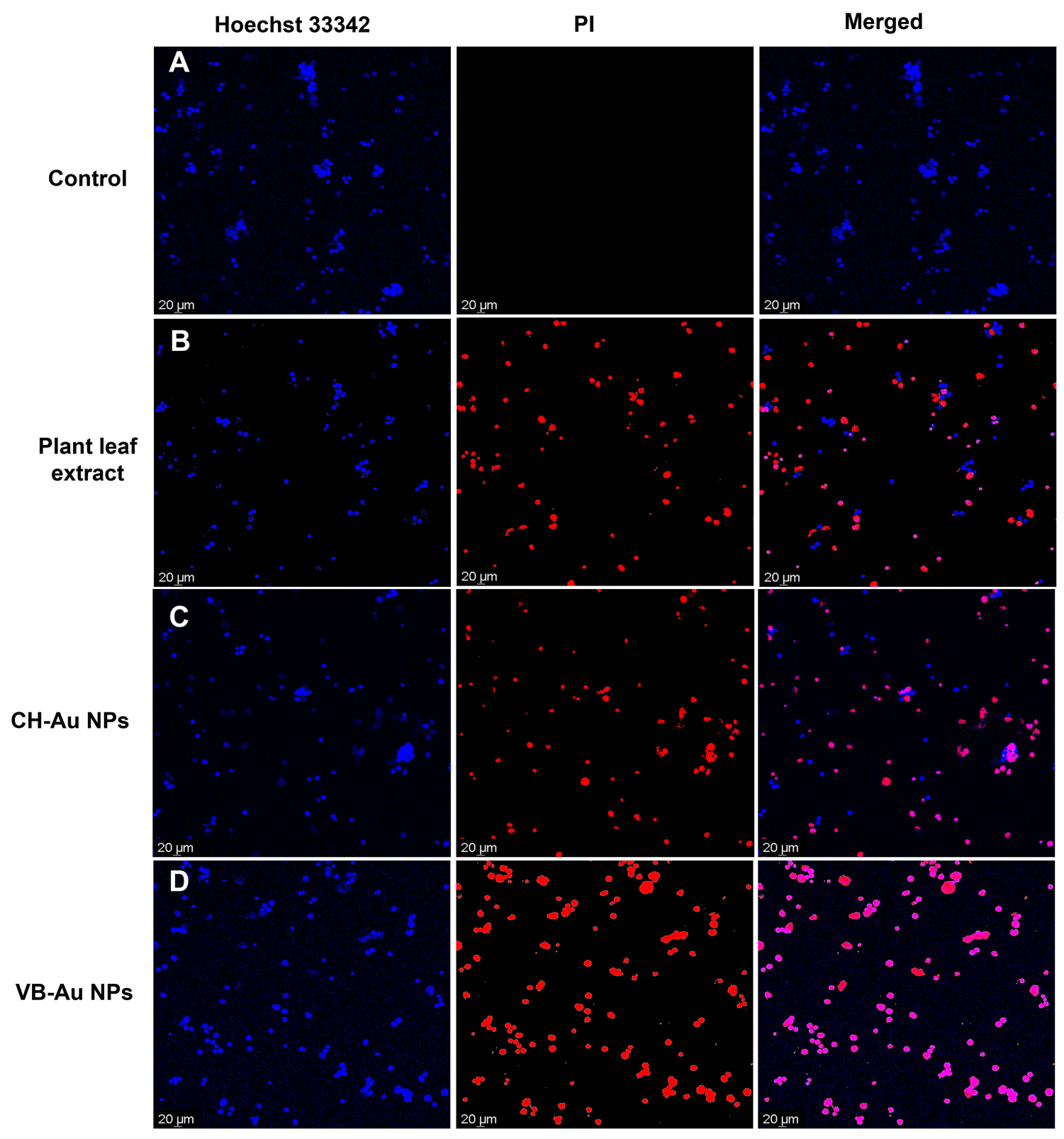

Figure I I CLSM images of MCF-7 cells before (A) control and after incubating with (B) plant extract, (C) CH-Au NPs and (D) VB-Au NPs.

phytomolecules from Viola betonicifolia leaves extract on the nanoparticle's surface could be responsible for the VBAu NPs' superior antioxidant activity. This is because the phytomolecules (polyphenols, flavonoids, etc.) of Viola betonicifolia leaf extract have various molecular functionalities $\left(-\mathrm{OH},-\mathrm{COOH}, \mathrm{NH}_{2}\right.$, etc.) that allow them to contribute electron pairs to electron-deficient centres or free radical moieties. ${ }^{20}$ When VB-Au NPs were treated with linoleic acid for 15 days, they significantly prevented peroxidation by donating electrons from oxygen or nitrogen atoms with molecular functionalities $(-\mathrm{OH},-\mathrm{COOH}$, $\mathrm{NH}_{2}$, etc.) of Viola betonicifolia leaf extract.
Consequently, fewer peroxide species are produced, which combine with ferrous chloride to make ferric ions. These ferric ions then react with ammonium thiocyanate to form ferric thiocyanate (Red in colour). In summary, antioxidant activity is inversely proportional to ferric thiocyanate production and vice versa. ${ }^{62,63}$

\section{Biocompatibility Evaluation of Green Synthesized VB-Au NPs}

The biocompatibility of VB-Au NPs was assessed with the hMSCs in vitro compared to the Viola betonicifolia leaves extract and $\mathrm{CH}-\mathrm{Au}$ NPs. The results are expressed as 

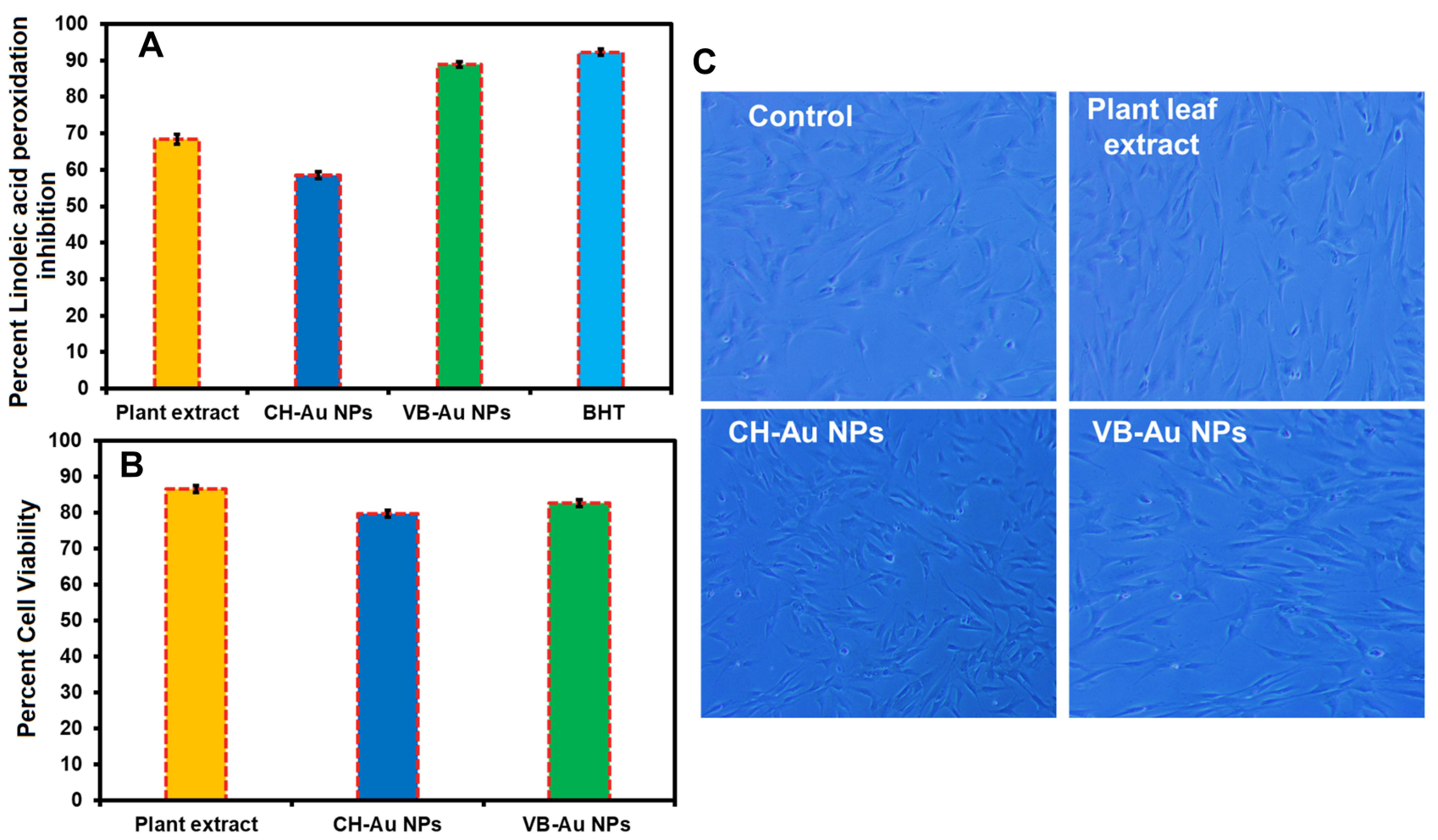

Figure 12 (A) Antioxidant activity of the newly synthesized VB-Au NPs in comparison to Viola betonicifolia leaves extract, $\mathrm{CH}-\mathrm{Au}$ NPs, and external standard (BHT) ( $p<$ $0.000 \mathrm{I}$ ). (B) Biocompatibility analysis of the newly synthesized VB-Au NPs with hMSCs compared to the leaves extract of Viola betonicifolia and CH-Au NPs ( $p<0.0002)$. (C) Inverted microscopic images of the hMSCs treated with plant extract, $\mathrm{CH}-\mathrm{Au}$ NPs, and VB-Au NPs.

a percentage of cell viability, as shown in Figure 12B. The findings indicated that $\mathrm{CH}-\mathrm{Au}$ NPs had the lowest cell viability percentage $(79.63 \pm 0.31 \%)$. On the other hand, newly synthesized VB-Au NPs demonstrated a cell viability percentage $(82.66 \pm 0.90 \%)$ with hMSCs. Additionally, it is noteworthy to mention that the extract of Viola betonicifolia leaves contains biocompatible secondary metabolites that demonstrated excellent biocompatibility (cell viability percentage $86.50 \pm 0.93 \%$ ) with hMSCs. It has been reported that different solvent extracts of Viola betonicifolia are safe to use and have no toxic effects. $^{20,22,64}$

We next used an inverted microscope to investigate the differential expression in hMSCs treated with VBL-Au NPs, plant extract, and CH-Au NPs at a $120 \mathrm{~g} / \mathrm{mL}$ concentration. Figure $12 \mathrm{C}$ is an inverted micrograph of hMSCs. The images show that the appearance of hMSCs remained similar to that of control cells after treatment with plant extract and VB-Au NPs. CH-Au NPs, but on the other hand, induced toxicity in hMSCs by decreasing their volume and cytoplasm and changing their structure. The cell viability results were found to be compatible with the inverted microscopy results. Consequently, it could be deduced that phytomolecules present in Viola betonicifolia leaves extract may indeed be liable for the VB-Au NPs' improved biocompatibility.

\section{Conclusion}

The synthesized VB-Au NPs presented excellent antibacterial, antifungal, and biofilm inhibition performance against all the tested microbial species compared to plant leaves extract and commercially purchased chemically synthesized gold NPs (CH-Au NPs). The synthesized VB-Au NPs displayed good cytobiocompatibility with hMSCs compared to $\mathrm{CH}-\mathrm{Au}$ NPs. Moreover, they also exhibited significant antioxidant and cytotoxic potential compared to plant leaves extract and $\mathrm{CH}-\mathrm{Au}$ NPs. The enhanced antioxidant, cytobiocompatibility, antibacterial, antifungal, and biofilm inhibition efficacy of VB-Au NPs compared to $\mathrm{CH}-\mathrm{Au}$ NPs might be attributed to the synergistic effect of the nanoparticle's physical properties, and the adsorbed biologically active phytomolecules from the leaves extract of Viola betonicifolia on their surface. Thus, our work offers a unique environmentally sustainable technique for manufacturing nanomaterials bestowed with enhanced and/or additional therapeutic properties obtained from their herbal sources. Additionally, further research should be performed to evaluate the 
effectiveness and dosage response of VB-Au NPs for clinical applications. The VB-Au NPs produced in this study may be used to develop antimicrobial coatings for medical equipments such as catheters, tubes, probes, and dressings, thus decreasing the prevalence of bacterial infections caused by biomaterials and biomedical devices.

\section{Acknowledgments}

The authors extended their appreciation to the Foundation of Guangdong Second Provincial General Hospital.

\section{Funding}

This work was supported by the National Natural Science Foundation of China (No. 81972083), Science and Technology Planning Project of Guangzhou (No. 202102080,202102010057), and the Foundation of Guangdong Second Provincial General Hospital (3DA2020004).

\section{Disclosure}

The authors declared no conflicts of interest.

\section{References}

1. Singh P, Kim YJ, Zhang D, Yang DC. Biological synthesis of nanoparticles from plants and microorganisms. Trends Biotechnol. 2016;34 (7):588-599. doi:10.1016/j.tibtech.2016.02.006

2. Riaz Rajoka MS, Mehwish HM, Xiong Y, et al. Gut microbiota targeted nanomedicine for cancer therapy: challenges and future considerations. Trends Food Sci Technol. 2021;107:240-251. doi:10.1016/J.TIFS.2020.10.036

3. Peralta-Videa JR, Huang Y, Parsons JG, et al. Plant-based green synthesis of metallic nanoparticles: scientific curiosity or a realistic alternative to chemical synthesis? Nanotechnol Environ Eng. 2016;1 (1):1-29. doi:10.1007/s41204-016-0004-5

4. Majdalawieh A, Kanan MC, El-Kadri O, Kanan SM. Recent advances in gold and silver nanoparticles: synthesis and applications. $J$ Nanosci Nanotechnol. 2014;14(7):4757-4780. doi:10.1166/jnn.2014.9526

5. Korbekandi H, Iravani S, Abbasi S. Production of nanoparticles using organisms Production of nanoparticles using organisms. Crit Rev Biotechnol. 2009;29(4):279-306. doi:10.3109/07388550903062462

6. Thakkar KN, Mhatre SS, Parikh RY. Biological synthesis of metallic nanoparticles. Nanomed Nanotechn Biol Med. 2010;6(2):257-262. doi:10.1016/j.nano.2009.07.002

7. Khan SA, Shahid S, Lee C-S-S. Green synthesis of gold and silver nanoparticles using leaf extract of Clerodendrum inerme; characterization, antimicrobial, and antioxidant activities. Biomolecules. 2020;10 (6):835. doi:10.3390/biom 10060835

8. Shankar SS, Rai A, Ankamwar B, Singh A, Ahmad A, Sastry M. Biological synthesis of triangular gold nanoprisms. Nat Mater. 2004;3 (7):482-488. doi:10.1038/nmat1152

9. Elbagory AM, Hussein AA, Meyer M. The in vitro immunomodulatory effects of gold nanoparticles synthesized from hypoxis hemerocallidea aqueous extract and hypoxoside on macrophage and natural killer cells. Int J Nanomedicine. 2019;14:9007-9018. doi:10.2147/IJN. S216972
10. Gharehyakheh S, Ahmeda A, Haddadi A, et al. Effect of gold nanoparticles synthesized using the aqueous extract of Satureja hortensis leaf on enhancing the shelf life and removing Escherichia coli O157: h7 and Listeria monocytogenes in minced camel's meat: the role of nanotechnology in the food industry. Appl Organomet Chem. 2020;34 (4): e5492. doi:10.1002/aoc.5492

11. Chandran SP, Chaudhary M, Pasricha R, Ahmad A, Sastry M. Synthesis of gold nanotriangles and silver nanoparticles using Aloe vera plant extract. Biotechnol Prog. 2006;22(2):577-583. doi:10.1021/bp0501423

12. Kumar V, Yadav SK. Plant-mediated synthesis of silver and gold nanoparticles and their applications. J Chem Technol Biotechnol. 2009;84(2):151-157. doi:10.1002/jctb.2023

13. Muthukumar T, Sudhakumari B, Aravinthan A, Sastry TP, Kim JH. Green synthesis of gold nanoparticles and their enhanced synergistic antitumor activity using HepG2 and MCF7 cells and its antibacterial effects. Process Biochem. 2016;51(3):384-391. doi:10.1016/j. procbio.2015.12.017

14. Khan SA, Lee C-S-S. Green Biological Synthesis of Nanoparticles and Their Biomedical Applications. Vol. 10. Springer Science and Business Media B.V;2020:247-280. doi:10.1007/978-3-030-44176-0_10

15. Riaz Rajoka MS, Mehwish HM, Zhang H, et al. Antibacterial and antioxidant activity of exopolysaccharide mediated silver nanoparticle synthesized by Lactobacillus brevis isolated from Chinese koumiss. Colloids Surfaces B Biointerfaces. 2020;186:110734. doi:10.1016/J.COLSURFB.2019.110734

16. Mehwish HM, Liu G, Rajoka MSR, et al. Therapeutic potential of Moringa oleifera seed polysaccharide embedded silver nanoparticles in wound healing. Int $J$ Biol Macromol. 2021;184:144-158. doi:10.1016/J.IJBIOMAC.2021.05.202

17. Mehwish HM, Rajoka MSR, Xiong Y, et al. Green synthesis of a silver nanoparticle using Moringa oleifera seed and its applications for antimicrobial and sun-light mediated photocatalytic water detoxification. $J$ Environ Chem Eng. 2021;9(4):105290. doi:10.1016/J.JECE.2021.105290

18. Hirpara DG, Gajera HP. Green synthesis and antifungal mechanism of silver nanoparticles derived from chitin- induced exometabolites of Trichoderma interfusant. Appl Organomet Chem. 2020;34(3):e5407. doi:10.1002/AOC.5407

19. Import Alert 45-06. Available from: https://www.accessdata.fda.gov/ cms_ia/importalert_119.html. Accessed September 18, 2021.

20. Rizwan K, Khan SA, Ahmad I, et al. A Comprehensive Review on Chemical and Pharmacological Potential of Viola betonicifolia: a plant with multiple benefits. Molecules. 2019;24(17):3138. doi: 10.3390/molecules24173138

21. Iqbal I, Hamayun M. Studies on the Traditional Uses of Plants of Malam Jabba Valley, District Swat, Pakistan. Ethnobot Leafl. 2005;2005(1):254.

22. Muhammad N, Saeed M, Khan H. Antipyretic, analgesic and anti-inflammatory activity of Viola betonicifolia whole plant. BMC Complement Altern Med. 2012;12(1):1-8. doi:10.1186/ 1472-6882-12-59

23. Muhammad N, Rehman N, Khan H, Saeed M, Gilani AH. Prokinetic and laxative effects of the crude methanolic extract of Viola betonicifolia whole plant in rodents. BMC Complement Altern Med. 2013;13(1):1-7. doi:10.1186/1472-6882-13-70

24. Zhu H, Qin SS, Zhang N, et al. Chemical Constituents and Biological Activities of Plants from the Genus Viola. Chem Biodivers. 2015;12 (12):1777-1808. doi:10.1002/cbdv.201400240

25. Alfuraydi AA, Devanesan S, Al-Ansari M, Alsalhi MS, Ranjitsingh AJ. Journal of Photochemistry \& Photobiology, B: biology Eco-friendly green synthesis of silver nanoparticles from the sesame oil cake and its potential anticancer and antimicrobial activities. J Photochem Photobiol B Biol. 2019;192(December2018):83-89. doi:10.1016/j.jphotobiol.2019.01.011 
26. Latha D, Sampurnam S, Arulvasu C, Prabu P, Govindaraju K, Narayanan V. Biosynthesis and characterization of gold nanoparticle from Justicia adhatoda and its catalytic activity. In: Materials Today: Proceedings. Vol. 5. Elsevier Ltd; 2018: 8968-8972. doi:10.1016/j. matpr.2017.12.337

27. Khan SA, Shahid S, Ayaz A, Alkahtani J, Elshikh MS, Riaz T. Phytomolecules-coated $\mathrm{NiO}$ nanoparticles synthesis using abutilon indicum leaf extract: antioxidant, antibacterial, and anticancer activities. Int J Nanomedicine. 2021;16:1757-1773. doi:10.2147/ IJN.S294012

28. Hussain A, Alajmi MF, Khan MA, et al. Biosynthesized Silver Nanoparticle (AgNP) From Pandanus odorifer Leaf Extract Exhibits Anti-metastasis and Anti-biofilm Potentials. J Photochem Photobiol B Biol. 2019;10(February):1-19. DOI:10.3389/fmicb.2019.00008

29. Kasprzak MM, Erxleben A, Ochocki J. Properties and applications of flavonoid metal complexes. RSC Adv. 2015;5(57):45853-45877. doi:10.1039/c5ra05069c

30. Mata R, Nakkala JR, Sadras SR. Polyphenol stabilized colloidal gold nanoparticles from Abutilon indicum leaf extract induce apoptosis in HT-29 colon cancer cells. Colloids Surfaces B Biointerfaces. 2016;143:499-510. doi:10.1016/j.colsurfb.2016.03.069

31. Valencia C, Valencia $\mathrm{CH}$, Zuluaga F. Synthesis and application of scaffolds of chitosan-graphene oxide by the freeze-drying method for tissue regeneration. Molecules. 2018;23(10):2651. doi:10.3390/ molecules23102651

32. Fekri LZ, Nikpassand M. Synthesis, experimental and DFT studies on the crystal structure, FTIR, 1H NMR and 13C NMR spectra of derivatives of dihydropyridines. J Chil Chem Soc. 2012;57 (4):1415-1421. doi:10.4067/S0717-97072012000400017

33. Patra JK, Baek KH. Novel green synthesis of gold nanoparticles using Citrullus lanatus rind and investigation of proteasome inhibitory activity, antibacterial, and antioxidant potential. Int J Nanomedicine. 2015;10(1):7253-7264. doi:10.2147/IJN.S95483

34. Ahmad T, Bustam MA, Zulfiqar M, et al. Controllable phytosynthesis of gold nanoparticles and investigation of their size and morphology-dependent photocatalytic activity under visible light. J Photochem Photobiol a Chem. 2020;392:112429. doi:10.1016/j. jphotochem.2020.112429

35. Feyzabadi Z, Ghorbani F, Vazani Y, Zarshenas MM, Critical A. Review on Phytochemistry, Pharmacology of Viola odorata L. and Related Multipotential Products in Traditional Persian Medicine. Phyther Res. 2017;31(11):1669-1675. doi:10.1002/ptr.5909

36. Ramalingam B, Parandhaman T, Das SK. Antibacterial Effects of Biosynthesized Silver Nanoparticles on Surface Ultrastructure and Nanomechanical Properties of Gram-Negative Bacteria viz. Escherichia coli and Pseudomonas aeruginosa. ACS Appl Mater Interfaces. 2016;8(7):4963-4976. doi:10.1021/acsami.6b00161

37. Arakha M, Saleem M, Mallick BC, Jha S. The effects of interfacial potential on antimicrobial propensity of $\mathrm{ZnO}$ nanoparticle. Sci Rep. 2015;5(1):1-10. doi:10.1038/srep09578

38. Kim JS, Kuk E, Yu KN, et al. Antimicrobial effects of silver nanoparticles. Nanomed Nanotechn Biol Med. 2007;3(1):95-101. doi:10.1016/J.NANO.2006.12.001

39. Khan SA, Shahid S, Shahid B, Fatima U, Abbasi SA. Green Synthesis of $\mathrm{MnO}$ Nanoparticles Using Abutilon indicum Leaf Extract for Biological, Photocatalytic, and Adsorption Activities. Biomolecules. 2020;10(5):785. doi:10.3390/biom10050785

40. Khan M, Shaik MR, Adil SF, et al. Plant extracts as green reductants for the synthesis of silver nanoparticles: lessons from chemical synthesis. Dalt Trans. 2018;47(35):11988-12010. doi:10.1039/ C8DT01152D

41. Huang J, Zhan G, Zheng B, et al. Biogenic silver nanoparticles by Cacumen Platycladi extract: synthesis, formation mechanism, and antibacterial activity. Ind Eng Chem Res. 2011;50(15):9095-9106. doi:10.1021/ie200858y
42. Khan SA, Shahid S, Hanif S, Almoallim HS, Alharbi SA, Sellami H. Green Synthesis of Chromium Oxide Nanoparticles for Antibacterial, Antioxidant Anticancer, and Biocompatibility Activities. Int $\mathrm{J} \mathrm{Mol}$ Sci. 2021;22(2):1-17. doi:10.3390/ijms22020502

43. Bindhu MR, Umadevi M. Antibacterial activities of green synthesized gold nanoparticles. Mater Lett. 2014;120:122-125. doi:10.1016/j.matlet.2014.01.108

44. Boomi P, Ganesan RM, Poorani G, Gurumallesh Prabu H, Ravikumar S, Jeyakanthan J. Biological synergy of greener gold nanoparticles by using Coleus aromaticus leaf extract. Mater Sci Eng C. 2019;99:202-210. doi:10.1016/j.msec.2019.01.105

45. Slavin YN, Asnis J, Häfeli UO, Bach H. Metal nanoparticles: understanding the mechanisms behind antibacterial activity. $J$ Nanobiotechnology. 2017;15(1):65. doi:10.1186/s12951-0170308-z

46. Rizzello L, Pompa PP. Nanosilver-based antibacterial drugs and devices: mechanisms, methodological drawbacks, and guidelines. Chem Soc Rev. 2014;43(5):1501-1518. doi:10.1039/C3CS60218D

47. Ramalingam B, Parandhaman T, Das SK. Antibacterial Effects of Biosynthesized Silver Nanoparticles on Surface Ultrastructure and Nanomechanical Properties of Gram-Negative Bacteria viz. Escherichia coli and Pseudomonas aeruginosa. ACS Appl Mater Interfaces. 2016;8(7):4963-4976. doi:10.1021/ACSAMI.6B00161

48. Sher M, Khan SA, Shahid S, et al. Synthesis of novel ternary hybrid g-C3N4@Ag-ZnO nanocomposite with Z-scheme enhanced solar light-driven methylene blue degradation and antibacterial activities. $J$ Environ Chem Eng. 2021;9(4):105366. doi:10.1016/J. JECE.2021.105366

49. Sarwar MN, Khan SA, Shahid S, Jabin S, Zaman S. synthesis and characterization of un-doped and copper doped zinc oxide nanoparticles for their optical and antibacterial studies synthesis and characterization of un-doped and copper-doped zinc oxide nanoparticles for their optical and antibacterial studies. Dig $J$ Nanomater Biostructures. 2018;13(1):285-297.

50. Shahid S, Fatima U, Shahid S, Fatima U, Sajjad R, Khan SA. Bioinspired Nanotheranostic Agent: zinc Oxide; Green Synthesis And Biomedical Potential. Dig J Nanomater Biostructures. 2014;14 (4):1023-1031.

51. Shahid S, Khan SA, Ahmad W, Fatima U, Knawal S. Size-dependent Bacterial Growth Inhibition and Antibacterial Activity of Ag-doped $\mathrm{ZnO}$ Nanoparticles under Different Atmospheric Conditions. Indian J Pharm Sci. 2018;80(1):173-180. doi:10.4172/PHARMACEUT ICAL-SCIENCES.1000342

52. Khan SA, Kanwal S, Rizwan K, Shahid S. Enhanced antimicrobial, antioxidant, in vivo antitumor and in vitro anticancer effects against breast cancer cell line by green synthesized un-doped $\mathrm{SnO} 2$ and Co-doped $\mathrm{SnO} 2$ nanoparticles from Clerodendrum inerme. Microb Pathog. 2018;125:366-384. doi:10.1016/J.MICPATH.2018.09.041

53. Khan SA, Noreen F, Kanwal S, Iqbal A, Hussain G. Green synthesis of $\mathrm{ZnO}$ and $\mathrm{Cu}$-doped $\mathrm{ZnO}$ nanoparticles from leaf extracts of Abutilon indicum, Clerodendrum infortunatum, Clerodendrum inerme and investigation of their biological and photocatalytic activities. Mater Sci Eng C. 2018;82:46-59. doi:10.1016/J. MSEC.2017.08.071

54. Ijaz F, Shahid S, Khan SA, Ahmad W, Zaman S. Green synthesis of copper oxide nanoparticles using Abutilon indicum leaf extract: antimicrobial, antioxidant and photocatalytic dye degradation activities. Trop J Pharm Res. 2017;16(4):743-753. doi:10.4314/tjpr.v16i4.2

55. Fanoro OT, Oluwafemi OS. Bactericidal Antibacterial Mechanism of Plant Synthesized Silver, Gold and Bimetallic Nanoparticles. Pharm. 2020;12(11):1044. doi:10.3390/PHARMACEUTICS12111044

56. Cui Y, Zhao Y, Tian Y, Zhang W, Lü X, Jiang X. The molecular mechanism of action of bactericidal gold nanoparticles on Escherichia coli. Biomaterials. 2012;33(7):2327-2333. doi:10.1016/ J.BIOMATERIALS.2011.11.057 
57. Katoch M, Singh A, Singh G, Wazir P, Kumar R. Phylogeny, antimicrobial, antioxidant and enzyme-producing potential of fungal endophytes found in Viola odorata. Ann Microbiol. 2017;67 (8):529-540. doi:10.1007/s13213-017-1283-1

58. Balasubramanian S, Kala SMJ, Pushparaj TL. Biogenic synthesis of gold nanoparticles using Jasminum auriculatum leaf extract and their catalytic, antimicrobial and anticancer activities. J Drug Deliv Sci Technol. 2020;57:101620. doi:10.1016/j.jddst.2020.101620

59. Dananjaya SHS, Thu Thao NT, Wijerathna HMSM, et al. In vitro and in vivo anticandidal efficacy of green synthesized gold nanoparticles using Spirulina maxima polysaccharide. Process Biochem. 2020;92:138-148. doi:10.1016/j.procbio.2020.03.003

60. Jayaseelan C, Ramkumar R, Rahuman AA, Perumal P. Green synthesis of gold nanoparticles using seed aqueous extract of Abelmoschus esculentus and its antifungal activity. Ind Crops Prod. 2013;45:423-429. doi:10.1016/j.indcrop.2012.12.019

61. Muhammad N, Saeed M, Adhikari A, Khan KM, Khan H. Isolation of a new bioactive cinnamic acid derivative from the whole plant of Viola betonicifolia. J Enzyme Inhib Med Chem. 2013;28 (5):997-1001. doi:10.3109/14756366.2012.702344

62. Mohd Adzim Khalili Rohin T. Total phenolic content and In vitro antioxidant activity of Vigna sinensis. Int Food Res J. 2012;19 (4):1393-1400

63. Huda-Faujan N, Noriham A, Norrakiah A, Babji A. Antioxidant activity of plants methanolic extracts containing phenolic compounds. African J Biotechnol. 2010;8(3):484-489. doi:10.4314/ ajb.v8i3.59849
64. Muhammad N, Saeed M, Khan H, Haq I. Evaluation of n-hexane extract of Viola betonicifolia for its neuropharmacological properties. J Nat Med. 2013;67(1):1-8. doi:10.1007/s11418-012-0636-0

65. Thakur M, Poojary S, Swain N. Green Synthesis of Iron Oxide Nanoparticles and Its Biomedical Applications. In: Nanotechnology in the Life Sciences. Springer Science and Business Media B.V; 2021:83-109. doi:10.1007/978-3-030-64410-9_5

66. Khan SA, Shahid S, Mahmood T, Lee C-S. Contact lenses coated with hybrid multifunctional ternary nanocoatings (Phytomolecule-coated $\mathrm{ZnO}$ nanoparticles: gallicAcid: tobramycin) for the treatment of bacterial and fungal keratitis. Acta Biomater. 2021;128:262-276. doi:10.1016/j.actbio.2021.04.014

67. Choi K-H-H, Nam KC, Lee S-Y-Y, et al. Antioxidant Potential and Antibacterial Efficiency of Caffeic Acid-Functionalized $\mathrm{ZnO}$ Nanoparticles. Nanomaterials. 2017;7(6):148. doi:10.3390/ nano7060148

68. Emam AN, Loutfy SA, Mostafa AA, Awad H, Mohamed MB. Cytotoxicity, biocompatibility and cellular response of carbon dots-plasmonic based nano-hybrids for bioimaging. RSC Adv. 2017;7(38):23502-23514. doi:10.1039/c7ra01423f

69. Iqbal S, Bhanger MI, Anwar F. Antioxidant properties and components of some commercially available varieties of rice bran in Pakistan. Food Chem. 2005;93(2):265-272. doi:10.1016/j. foodchem.2004.09.024
International Journal of Nanomedicine

\section{Publish your work in this journal}

The International Journal of Nanomedicine is an international, peerreviewed journal focusing on the application of nanotechnology in diagnostics, therapeutics, and drug delivery systems throughout the biomedical field. This journal is indexed on PubMed Central, MedLine, CAS, SciSearch ${ }^{\mathbb{}}$, Current Contents ${ }^{\mathbb{R}} /$ Clinical Medicine,

\section{Dovepress}

Journal Citation Reports/Science Edition, EMBase, Scopus and the Elsevier Bibliographic databases. The manuscript management system is completely online and includes a very quick and fair peer-review system, which is all easy to use. Visit http://www.dovepress.com/ testimonials.php to read real quotes from published authors. 